Portland State University

PDXScholar

5-4-1971

\title{
Expanding the Visual Potential of Subject Matter Through Two-Dimensional Design
}

William Paul Paxton

Portland State University

Follow this and additional works at: https://pdxscholar.library.pdx.edu/open_access_etds

Part of the Art and Design Commons, and the Art Education Commons Let us know how access to this document benefits you.

\section{Recommended Citation}

Paxton, William Paul, "Expanding the Visual Potential of Subject Matter Through Two-Dimensional Design" (1971). Dissertations and Theses. Paper 1501.

https://doi.org/10.15760/etd.1500

This Thesis is brought to you for free and open access. It has been accepted for inclusion in Dissertations and Theses by an authorized administrator of PDXScholar. Please contact us if we can make this document more accessible: pdxscholar@pdx.edu. 
AN ABSTRACT OF THE THESIS OF William Paul Paxton for the Naster of Science in Teaching presented May 4, 1971.

Title: Expanding the Visual Potential of Subject Watter Through Two-dimensional Design.

APPROVED BY MELBBERS OF THE THESIS COMRITTEE:

- By̆rof J. Gafdner, Chairman

Frederick-H. Heidel

Iard Kimbrell

Richard J. Prasch

This research problem represents an attempt to forestall the high school student's usual preoccupation with perceptive minutiae by placing an emphasis on the monumental or underlying structure of a work of art.

The author, endeavoring to afford maximum success for the students, first stripped subject matter to its most pristine quality, the silhouette. Because it was felt that it is much easier to recognize and organize an underlying structure without the added complication of perspective, emphasis was placed on a depthless surface or decorative space to be organized into a coherent whole through application of the 
abstractions which are the elements and principles of design.

This unit was offered to a class of high school students in an Nut General class at Madison High School, Portland, Oregon. This is an elective class open to all students from freshman to senior year.

Results of this unit were generally successful. Improvement was exhibited by all students. During these activities of experimenting and creating, students learned about design by doing, looking, and discussing. They became less concerned about minutiae, and they began to express an appreciation for paintings for themselves rather than for recognizable objects or superfluous delineation.

It was concluded that students at this age level have the most difficulty when left to their ow resources for subject matter. Wany false starts were made before this particular problem was resolved. But, upon its completion, students felt that they had met a challenge of discovery, exploration, and creation on their own. 
EXPANDING THE VISUAL POTENTIAL OF SUBJECT MATTER THROUGH TWO-DIMENSIONAL DESIGN

by

WILIIAU PAUL PAXTON

A thesis submitted in partial fulfillment of the requirements for the degree of

MASTER OF SCIENCE in TEACHING

in ART

Portland State University

1971 
TO THE OFFICE OF GRADUATE STUDIES:

The members of the Committee approve the thesis of William Paul Paxton presented May 4, 1971.

Byron J. Gardher, Chairman

Frederick H. Heidel

Leonard Kimbrell

Richard J. Prasch

APPROVED:

Frederick H. Heidel, Head, Department of Art

David T. Clark, Dean of Graduate Studies

May 17,1971 
TABLE OF CONTENTS

PAGE

IIST OF FIGURES . . . . . . . . . . . . . . . .

CHAPTER

I DESCRIPTION OF THE PROBLEM . . . . . . . . .

II A SUGGESTED APPROACH TO THE SOLUTION OF THE

PROBLEM ....................

II METHODS AND TECHNIQUES . . . . . . . . .

I. The Silhouette and Flat Shape

Relationships ............

II. Iine Exploration and Abstract Relationship of Shapes in Space ............

III. Exploration of Color and Flat Shapes

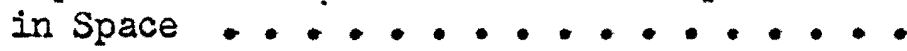

IV CONCLUSTON $\cdot \cdot \cdot \cdot \cdot \cdot \cdot \cdot \cdot \cdot \cdot \cdot \cdot \cdot \cdot \cdot \cdot \cdot$

A ITST OF WORKS CONSULTED ................ 


\section{IIST OF FIGURES}

FIGURE

PAGE

1. Results of Problem 2, p. 8. ......... 34

2. Results of Problem 2, p. 8 (continued). ...... 35

3. Results of Problem 2, p. 8 (continued). ...... 36

4. Results of Problem 3, p. 8. ......... 37

5. Results of Problem 3, p. 8 (contimed). ..... 38

6. Results of Problems 1, 2, and 3, p. 10. ..... 39

7. Results of Problems 1, 2, and 3, p. 10 (continued). - 40

8. Results of Problem 4, p. 11. .......... 41

9. Results of Problem I, p. 13. .......... 42

10. Results of Problem 1, p. 13 (continued). ...... 43

11. Three views of display, Problem 2, p. 15. ...... 44

12. Results of Problem 2, p. 15. .......... 45

13. Results of Problem 2, p. 15. .......... 46

14. Results of Problem 2, p. 15 (continued). ..... 47

15. Results of Problem 3, p. 19. ......... 48

16. Results of Problem 3, p. 19 (continued). ..... 49

17. Results of Problem 3, p. 19 (continued). ..... 50

18. Results of Problem 4, p. 26. ........... 51

19. Results of Problem 4, p. 26 (continued). ..... 52

20. Results of Problem 4, p. 26 (continued). ..... 53

21. Results of Problem 4, p. 26 (continued). ..... 54 


\section{CHAPTER I}

\section{DESCRIP'PION OF THE PROBLEM}

However they may choose to call them, most artists will agree that a successful work of art is dependent upon the organization of abstract devices generally called elements of design: line, form or shape, value (varied lights and darks), color, texture, pattern, and space. The organization of these elements is accomplished by incorporating the principles of design: balance, rhythm, domination, selection, repetition, and so on, and is called composition. And, "Composition may be as complex as an immense canvas by Rubens or as simple as a rectilinear painting made from a few lines and colours by Mondrian."I

According to Erle Loran, " . In Cézanne the highest degree of expressiveness, of freedom and liberation was based on certain factors of composition that every artist should know."2 surely then, the statement which Watson attributes to Loran, "The one certainty is that no painting, ancient or modern, has achieved significance that does not contain in its internal structure the elements of abstract order. $n^{3}$ is pertinent for the teaching of art today.

IFred Gettings, You Are An Artist (London, 1965), p. 63.

2 Erle Loran, Cézanne's Composition, 2nd ed. (California, 1946), p. 33.

3 Ernest W. Watson, Composition in Landscape and Still Iife (New York, 1959), p. 25. 
Among the first dificulties experienced by beginners in art is that they cannot see the forest for the trees. Trees may be a part of the over-all picture to which they may supply color. However, the artist must look for the monumental or grand pattern rather than the minutiae. This is not found in an inventory of facts but in design. Details should be organized into an harmonious plan. This leads to simplification and the establishing of an underlying structure or pattern which must always control every detail that is added to enrich it. 4

Simplification is an understatement of details, and "... the greater the simplification - . the more the painter is likely to draw upon his own creative powers and give us expression rather than illustration. 15

How far should simplification go to begin an introduction of design and structure to beginners?.

4riatson, p. 58 .

5ifatson, p. 15. 
One way to begin a course in design for beginners who have the tendency to become overly involved with minutiae was suggested by a statement of Nicolaides:

When a boat comes out of the fog, you see first the large simple forms. As it comes closer, you see more. Each detail grows in place and with the same relationship to all the other details that it had at first. The details do not suddenly leap out at you but appear by gradual transition. Nothing is applied. Everything grows out of the thing itself. The thing grows and the details are the crescendo of the form. You put the cart before the horse if you put them first.6

The large simple forms he refers to mast be the silhouette. This word is seldom found in books on design, but it has been found easier to use than mass, shape, or form in describing this phenomenon to high school students. Perhaps it is more personal or meaningful to them. By dictionary definition, a silhouette is an outline of some object filled in with a uniform color or any dark shape or outline seen against a light background. ${ }^{7}$ For our purposes, it is a flat shape, completely stripped of all details, existing in a certain space, thus a simplification of the object and a step toward monumentality and underlying abstract order. Abstract order, which in many paintings may

6 Kimon Nicolaides, The Natural Way to Draw (Boston, 1941), p. 91. 1956). Webster's New World Dictionary, College Edition, (New York, 
be hidden from the untrained eye, is almost the only part that gives it any importance whatever. 8

To the artist's perceptive eye nature is basically abstract, and simplification is the key to its realization by eliminating meaningless detail and reorganizing the disparate elements into a plan in which colors - or parts and their shapes - fall into a prearranged de$\operatorname{sign.} 9$

Stripping the shape to its most pristine quality is the foundation of this attempt to alter the beginner's approach. "The shape in its most elementary form is a flat silhouette." 10 The emphasis is thus placed upon the relationship of the flat shape to the edges of the picture plane on which he is working. When a number of shapes are involved, the negative spaces become more vivid because there are no details to confuse or distract the eye.

The two-dimensional surface of the picture plane is emphasized. The flat surface on which the beginner works can be considered as decorative space or " - . a space which exists across the picture plane rather than in it." 11

Such restrictions have their benefits. There is no necessity to worry about linear perspective or other means for suggesting deep or illusionistic space. The purpose of flattening out deep space is to

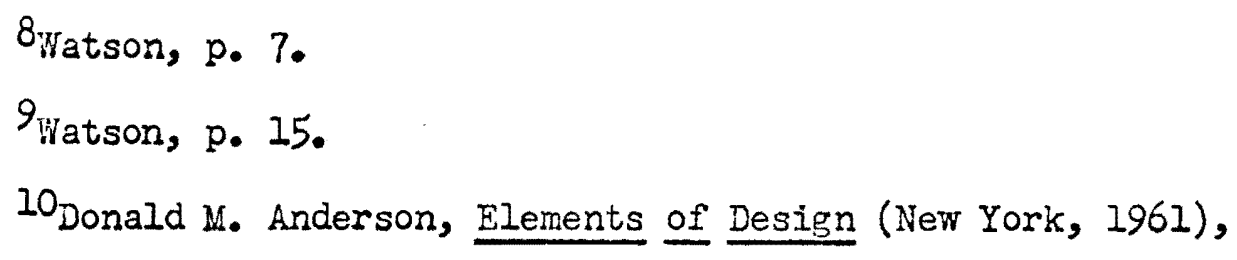
p. 85.

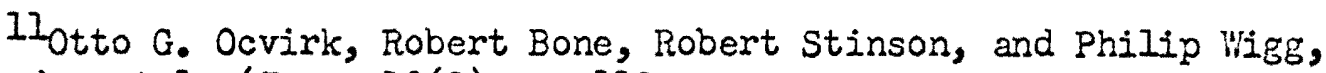
Art Fundamentals (Iowa, 1960), p. 110. 
focus upon two-dimensional design and the design of space that encompasses objects. This intention is likely to be thwarted by preoccupation with deep space. ${ }^{12}$

Also, by shifting emphasis away from deep space, students can relax and enjoy the construction of designs and sharpen their perception and intuition by experiments with the elements and principles of pictorial organization as they are introduced and explained. 13

This unit was designed for students in what is called an Art General class at Madison High School, Portland, Oregon. These are not selected students. Classes include students from freshman to senior year in school. In these classes we attempt to give the student a sampling of as many art experiences as possible, such as drawing, painting, sculpture, and printmaking, with as many media as we have at our disposal. So, an attempt has been made to incorporate experiences and instruction in several different media together with the elements of pictorial organization.

Students were not required to learn and recite by rote the elements or principles of design under their proper headings. However, the vocabulary for describing their own work and that of others was reinforced by class critiques and each individual's written evaluation of his own work and what he had learned from the assignment. It didn't seem necessary for this unit to have them learn that by some authors such things as line, shape, value, color, texture, and space were called elements of design and that balance, rhythm, domination,

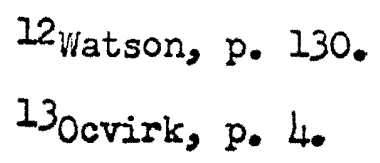


unity, and selection were called principles of cesign. It only seemed necessary that these words meant something in relationship to their construction of a painting, and that they were able to use them in identifying their visual occurrence in a painting. They were advised, however, that the elements of design were visual abstractions whose use could create the non-visual or "felt" abstractions of the principles of design. 


\section{CHAPTER III}

\section{DETHODS AND TECHNIQUES}

\section{THE SILHOUETTE AND FLAT SHAPE REIATIONSHIPS}

Problem 1.

Using brush and ink, students washed in the silhouette of the model. They were to work from the center of the figure to its extremities always considering the gesture of the figure.

The model was posed in front of a window and room lights were turned out so that a maximum silhouette could be obtained.

Washes were to be large and free to utilize the entire sheet of eighteen by twenty-four inch newsprint. Students were to forget minutiae and consider the figure's relationship to the edges of the sheet of paper. Also, they were not to be concerned if drawings ran off the edges of the paper as these were throw-away exercises. The poses were from five to twenty minute duration.

Since the beginner is usually only aware of the dark shapes he is making, discussions were held regarding positive and negative space in order to develop appreciation and sharpen sensitivity to the white shapes being created as a result of the dark shapes made on the paper. 14

The following reproductions of paintings were shown on an opaque projector to illustrate the relative flatness of the figure as a sil-

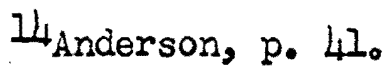


houette and its design qualities in painting:

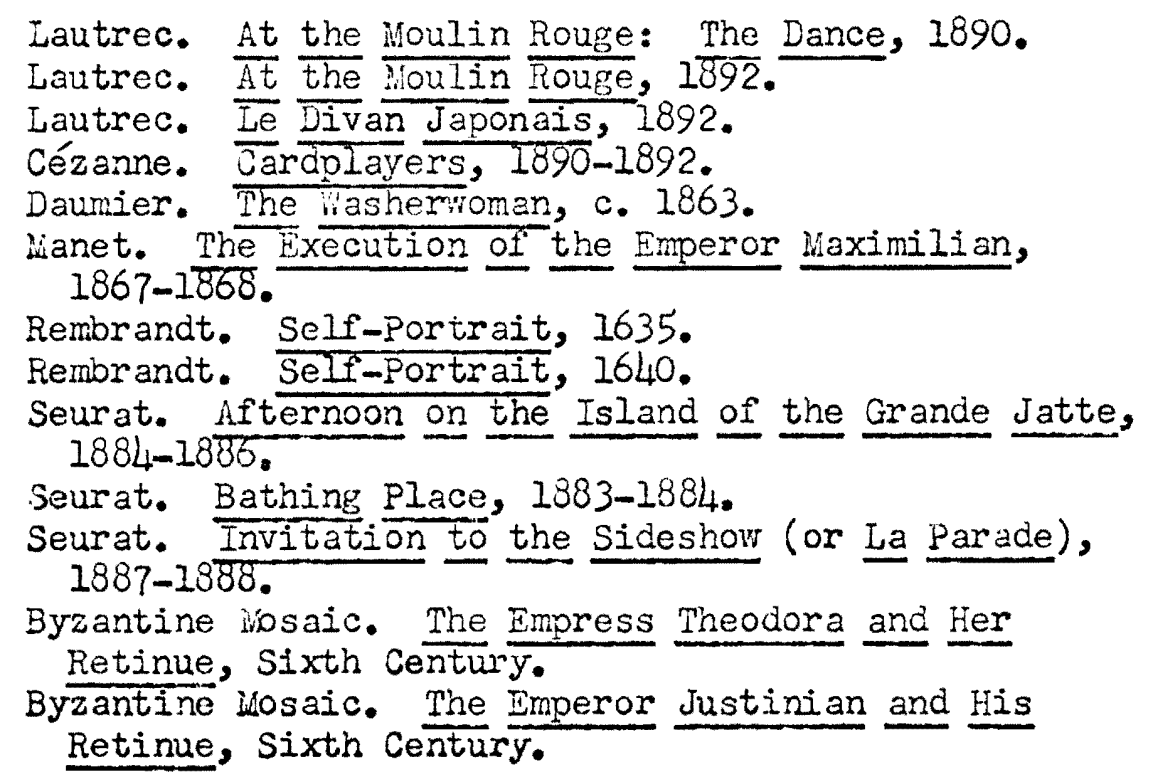

Problem 2.

For this problem the model did not stand in front of the window. Students were to wash in a light colored silhouette of the figure gesture. Having established the original silhouette, darker washes were to be used to record the abstract shapes within the larger silhouette which would serve to further describe the figure. Darker washes were to be flat designed shapes. Students were referred to reproductions exhibited. Poses were from five to twenty minutes duration.

\section{Problem 3.}

Beginning with the silhouette and dark washes as in Problem 2, students were to add lines where it was deemed necessary to further describe or emphasize the abstract shapes on the flat surface.

In these drawings students were to suggest environment by the simple development of negative space with flat, colored, geometric shapes. These were to be in the nature of completed drawings. Two 
period or more were to be allowed for completion.

In critiquing these drawings, students noted that "... light and shadow imply a basic abstraction - the abstraction involving the fixing of what is in a state of flux, i.e. [sic] the light source, [sic] and the position of the spectator's eye relative to the object seen." 15

They noted that, because of their more abstract characteristics, the light or negative shapes were harder to grasp and would be difficult to draw from memory. Contrasting darks have dramatic and involved contours and also a recognition factor. When drawings were turned upside down and sideways, students were better able to see positive and negative space relationships. 16

\section{LINE EXPLORATION AND ABSTRACT RELATIONSHIP \\ OF SHAPES IN SPACE}

This assignment was posed as a graphic problem of abstract relationships of shapes in space. The presentation included a demonstration of how one small black square placed on a sheet of white paper establishes a relationship between the black and white surfaces, and how the addition of a second black square destroys the first relationship and establishes a new one. Each time a new black square is added a new design is created. "It is this continual destruction and re-creation which is the basis of the art process . . ."17

15 Maurice de Sausmarez, Basic Design: The Dynamics of Visual Form, ed. John Lewis (New York, 1964), p. 56.

16 Anderson, p. 28 .

17 Gettings, p. 30 . 
From a graphic point of view, the black square is just a dot in one dimension, but, when placed within a white rectangle, it establishes a relationship with the sides and area of the rectangle and becomes a point of tension because of the force it exerts.

Problem 1.

A sheet of black construction paper was cut into small squares. Students were to arrange rows of black squares into a structured pattern using only vertical, horizontal, or diagonal directions. Squares were to be pasted down with rubber cement.

Students noted that tensions were established by introducing one or two black squares to the surface, but, when they are placed in a definite order, they lose their individuality and turn into a line with force and direction.

They then compared the difference in the lines created by black squares and a line made in the same length and breadth of a single piece of black paper. They noted that the first line was more lively but did not have the same strength of direction.

\section{Problem 2.}

On a second sheet of paper, students were to create a design using only curvilinear, rhythmic movements in their placement of black squares.

This design was found to be more lively when compared with the more subdued and formal movements of the first design.

Problem 3.

On a third sheet of paper, students were to combine the first 
two designs into one without destroying the basic underlying structure of the first design.

Students discovered that by combining the two designs, they had built up shapes or masses by overlapping and experienced the different abstract formal natures of points, lines, and shapes in space.

They also investigated the potential movement of rectilinear and curvilinear shapes and lines and found that, in general, ". . the latter appear to move more swiftly than the former." 18

Problem 4.

Klee collected and studied natural form and understood it not as isolated fragments but in terms of a whole environmental pattern. He appreciated the linear aspects of natural form - the seeking tendril, the relentless etch of line as revealed in cut sections of plants - and incorporated them into his own style of quiet fantasy. 19

This problem was designed to make the three previous problems more relevant to the fact that artists see nature as abstraction. A two inch section of a leaf was used as subject matter. Students worked with pen, brush, and ink.

The problem was to investigate and describe visually any patterns and varieties of thick and thin lines observed in the leaf formation. Students were to search out design as it actually can happen in nature and begin to be selective of what to use for their ow design purposes. Some areas created by line could be left blank, somo could be filled in with black, and some could be patterned as observed

$$
\begin{aligned}
& 18_{\text {de Sausmarez, }} \text { p. } 51 . \\
& 19_{\text {Anderson, p. } 57 .}
\end{aligned}
$$


in the leaf. According to Gettings, "The study of abstract relationships in terms of lines, masses, and forms gradually takes hold of the mind and begins to change one's awareness of the world."20

Students were to enlarge their designs from the two inch leaf section to an eighteen by twenty-four inch sheet of white drawing paper. They were to activate the entire surface and consider all shapes and lines in relation to the edges.

Students found that "The actual appearance of things is essentially different from the quick pre-conditioned glance of recognition that serves the purpose of every-day living."2l They observed that, when concern for a mechanical rule of perspective was not involved, an immense and varied field of variety of spatial representation could be achieved through qualities such as: length of lines, width of lines, the angles of inclination, and the position of lines relative to the edges of the picture space. 22 .

They found values in the contrasts of dark and light which a line exhibits against its background due to its thick and thin characteristics. Patterned areas formed by groups of single lines were noted to show value differences. 23

They also observed that abstract patterns emphasize the flatness of a picture plane because of their decorative quality. 24 Through

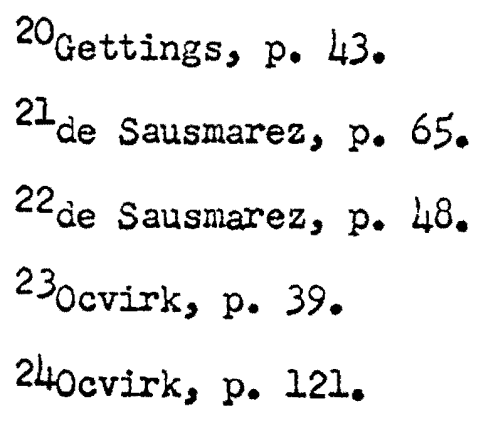


these observations, students were able to understand that lines have a value of their own - that they are more than mere outlines of the thing they represent. 25

III. EXPLORATION OF COLOR AND FLAT SHAPES IN SPACE

Knowledge of the laws of design need not irmprison, it can liberate from indecision and vacillating perception. What we call laws of color, obviously, can be no more than fragmentary, given the complexity and irrationality of color effects.

In the course of time, the human mind has penetrated many mysteries in their essence or in their mechanism - the rainbow, thunder and lightning, gravity and so on. But they are still mysteries for all that. 26

\section{Problem 1.}

To explore the potential of creating a painting using only one color through an investigation of its many values, students were assigned a monochromatic painting. As a further limitation, only a chair was used as subject matter - one color, one object. "A limitation of materials is perhaps the greatest stimulus to inventiveness." 27 Students were to develop as many values of the one color as possible using black, white, or gray. They were to design the background and the component parts of the chair as flat shapes.

The following reproductions were displayed to show how many paintings might fall into a one color category:

Van Gogh. The Chair and Pipe, 1888-1889.

25 Gettings, p. 46.

26Johames Itten, The Art of Color, trans. Ernst van Haagen (New York, 1961), p. 12.

27 de Sausmarez, p. 51. 
Van Gogh. Sunflowers, 1888.

Van Gogh. Gauguin's Chair, 1888-1889.

Remorandt. Self-Portrait, 1650.

Rembrandt. The Slaughtered Ox, 1655.

Warquet. County Fair, Le Havre, 1906.

Titian. The Three Ages of Han, 1510-1515.

Ryder. The Forest of Arcen, 1888.

Byzantine losaic. Christ as a Greek Shepherd, Ravenna, Fifth Century.

To make each value appear isolated and concrete, a black line was to surround each shape. 28 Because there are no outlines in nature, their use tends to contradict any illusion of deep space by flattening forms and serves the painter's arbitrarily designed picture space. 29

Since "The end and aim of all artistic endeavor is liberation of the spiritual essence of form and color and its release from imprisonment in the world of objects." 30 , students were allowed to choose a color arbitrarily for this problem.

Students were instructed to paint color samples of all values used in the painting on a separate sheet of paper - at least ten or fifteen. When the painting was completed, students were to cut samples into one by two inch rectangles and arrange them in rows from lightest to darkest and label the highest intensity color as it appeared on the chart. Opaque tempera paint was used as the medium.

Students enjoyed making a value chart in this manner. Some had made them before and felt that using the values in a painting at the same time had made the task a delight, and they were amazed that they

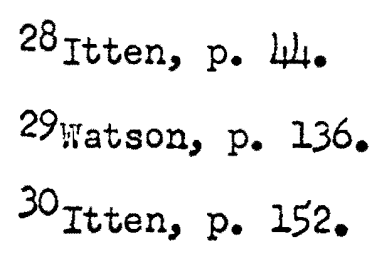


had achieved so nany. When the work of the entire class was exhibited, the students observed that ". - each hue may be lightened towards wite or darkened towards black in regular steps." 31 They also noted the relationship of the different pure colors to black and white values as they appeared on the charts and the warm and cool quality of colors which was exhibited in the different paintings.

They compared the flatness of the chart with that of the painting and noted that the painting, although rendered in flat shapes, had much more movement because the eye is predisposed to pursue a Iinear direction either by following an actual line or by an attraction of similar shapes, values, or colors which discourage the eye from concentration at any one point. 32

They also observed that, although the values were all painted as flat shapes, they exhibited advancing and receding characteristics. 33

\section{Problem 2.}

To explore the possibilities of using the three primary colors in a painting and the difficulties which might be experienced in establishing harmonious and balanced relationships with them, a display of not necessarily beautiful objects was erected to serve as subject matter reference. As Watson quotes PIato, "It is beauty I seek, not beautiful things. 134

This problem was manifold. It also involved decisions of

$31_{\text {Itten, p. } 56 .}$

32 de Sausmarez, p. 70.

330 cvirk, p. 61 .

34 iflatson, p. 23. 
selection. The display was not to be copied as a ready-made still Iife. Students were to feel free to move about the display to select objects, shapes, patterns, textures, and so on, for their paintings. Relative sizes of their selections could be changed or adjusted if it was felt necessary for the overall design of their picture plane.

Students were to work with forms that were painted flatly and to view their work from a distance from time to time to see if what they had considered to be a strong form close-up was not too weak from a distance and lacking in visual interest.

Intentionally, none of the objects had any striking local color of its own. This was to strengthen the idea that the artist's decision as to the best color relationships as they relate to his composition is of greater importance than any attempt at reproducing the local color of any object. "A more expressive use is achieved when the artist disassociates the color surfaces in the painting from the object to which the color supposedly belongs."35 "over many years of activity, Matisse increasingly negated local color and modeling in light and shade. His paintings became more and more flat and abstract. 136

The presentation of this problem included a showing of the film The Educated Eye (Bailey Films; property of Portland School District No. 1.) in which many elements of design as they relate to composition are illustrated. In addition, the film concentrated on the quality of selection as a most important decision for the artist in the act of

$$
\begin{aligned}
& 350 \text { cvirk, p. } 95 . \\
& 36_{\text {Itten, p. } 100 .}
\end{aligned}
$$


picture-making. It emphasized the fact that nature and art are not the same thing.

Primary and secondary colors were reviewed with the aid of a color wheel. Contrasts in hue, warm and cool, light and dark, and intensity were discussed.

Paul Klee's Garden in Bloom, 1930, which is designed only with colored rectangles, was used to demonstrate how a kind of movement can be effected simply by the way colors are placed next to one another. n. Klee placed red squares next to blue ones because he knew that the red would advance and the blue recede, thus creating a depth of tensions so that the picture area would appear to be vibrating with Iife."3? "It is an essential point that the effect of a color is determined by its situation relative to accompanying colors. 38

A reproduction of L'Eglise d'Ephese from the eleventh-century manuscript "Apocalypse de Saint Sever"39 was shown to demonstrate how the contrast of hues, that is ". . undiluted colors in their most intense luninosity" 40 can be used to create a painting of "grandiose truths."4I In this painting, students were to observe that yellow is the most dominant color 42 and "Color dominance is just as important to the unity of a picture as form and value dominance. $" 43$

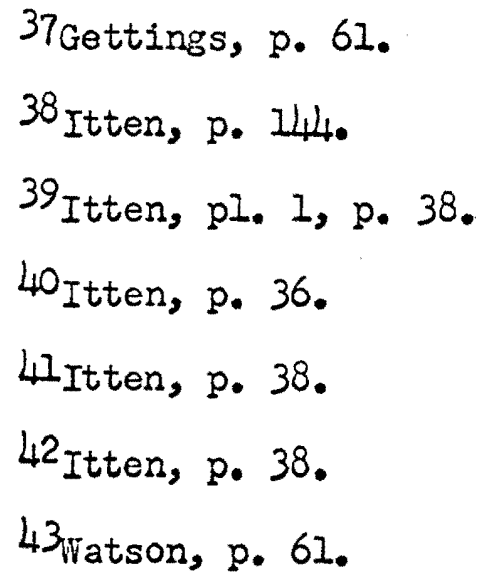


A reproduction of Paul Gauguin's painting The Vision After the Sermon (Jacob Wrestling with the Angel), 1888, was shown to explain the use of arbitrary color "for the purpose of adding intensity to personal views" and as a "method of obtaining stronger reaction in the viewer." 44 It was explained that certain local color was represented in the painting but, that, as Van Gogh is quoted by Anderson, "Instead of trying to reproduce exactly what I have before my eyes, I use color more arbitrarily so as to express myself forcibly .. .1145

Having first made preliminary sketches in pencil for their intended paintings, students were given a selection of materials to use as they desired: tissue paper for developing secondary colors by overlap, white glue, opaque tempera paint, crayons, transparent watercolor paint, felt pens, brushes, and eighteen by twenty-four inch drawing paper.

During the class critique, students expressed an awareness of the artist's function to create his own beauty instead of copying it from a carefully selected subject having an obvious beauty or attraction for him.

Students were able to discuss their paintings in terms of abstractions such as line, shape, value, pattern, color, texture, and space rather than things. They noted how the paintings differed in selection of objects and design. In some they determined that the emphasis was on pattern, other on texture, color, or line. Some, they noted, relied in various degrees upon the subtle orchestration of all

$$
\begin{aligned}
& 44_{\text {Anderson, p. } 196 .} \\
& 45_{\text {Anderson, p. } 200 .}
\end{aligned}
$$


abstract elements. 46

They noted the use and effectiveness of line over open color which is ".. now a familiar approach in contemporary painting and .. one of the outgrowths from the fountain source, Cézanne."147

They observed how freedom of choice and viewing their work from a distance had emboldened them in rendering strong forms and color reIationships. "There is not manch chance of making the relationships too gross for the nervous system to put together. Fear not to work boldy." 48

They expressed awareness that a repetition of similar color tones in different parts of the composition created a feeling of unity and balance. 49 In most of the paintings, a dominance of one color could be discerned when they squinted at it.

Students recognized the advancing and receding characteristics of certain colors and that, in general, warm colors seem to advance and cool colors seem to recede. They found that advancing and receding colors also create backward and forward movements in space giving liveliness and interest to the picture surface. 50

\section{Problem 3.}

"Subjective taste cannot suffice for the solution of all color

$$
\begin{aligned}
& \text { 46 Watson, p. } 14 . \\
& \text { 47 Loran, p. } 112 . \\
& 48 \text { Anderson, p. } 39 . \\
& \text { 490cvirk, p. } 99 . \\
& 50 \text { ocvirk, p. } 96 .
\end{aligned}
$$


problems. Knowledge of objective principles is essential to the correct evaluation of use of colors." 51

To explore some of the characteristics of complementary and analogous colors, students rere given an assignment which also incorporated some of the icieas developed in cubism such as unity of the two-dimensional picture surface 52 and simultaneity which shows the object "from as many views as suited the discrimination of the artist. 1153

An opaque projector was used to show the following reproductions to illustrate some of the qualities of cubist painting such as simultaneity, transparency, fragmentation, collage, contracted space, distortion, and texture or variation within the painted surface.

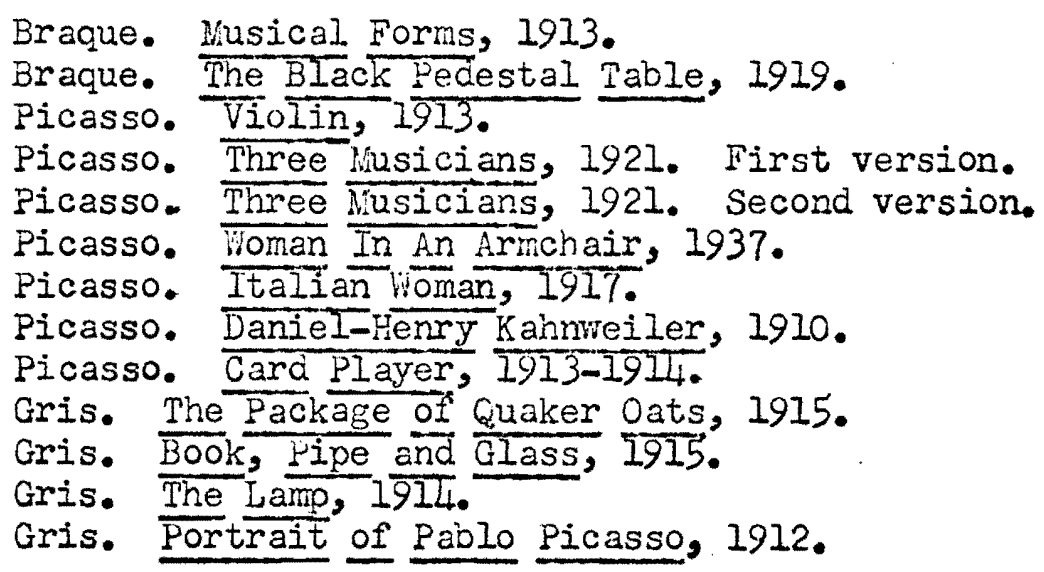

The qualities of cubism were explained as being an attempt to represent the movement of an object in space. On a two-dimensional

51 Itten, p. 32.

52 Peter and Linda Wurray, A Dictionary of Art and Artists, 3rd ed. (Great Britain, 1963), p. 76.

530 cvirk, p. 122. 
surface, motion becomes a part of space and a certain period of time is necessary to cover it. This presents a graphic challenge of presenting the elements of space, time, and motion which had been started by paul cézanne.

Simultaneity, the juxtaposition of several views of an object in one painting, showed much more of an object than would normally be visible. 54

Transparency is the "idea of making the invisible visible - the exercise of intellectual realism. 155 This allows two objects to be seen at the same time, creating a new shape as they overlap. The lay spectators view this new shape as distortion of the object. 56

By trying to arrive at a more permanent type of order than that found in nature, "paintings were now made with the intention of primarily emphasizing the artistic devices for their own sake rather than merely adapting these devices to the imitation of nature. 157

"The cubists discovered that we can read and interpret familiar shapes even across a complete change of color and outline. 158

Texture is used by the artist to inform and to provide needed variation. It provides a change of pace while defining space and shape. "Texture fits concept, and may range from careful imitation

54 ocvirk, p. 122 .

55 Anderson, p. 174 .

56 ocvirk, p. 122 .

57 ocvirk, p. 144.

58E. H. Gombrich, Art and Ilusion, 2nd ed. (Tennessee, 1965), p. 285. 
through abstraction to pure invention. Actual textures are sometimes substituted for initation. "59 The term collage came about through tinis substitution of texture and pattern by cubist artists. "In any case its general function is still to give life, variety, and richness to the work. "60

The color wheel was again referred to for a review of complementary and analogous colors. ". - some individuals have a preference and a flair for certain contrasts [in color] and experience difficulty in handling others. Each student needs a grounding in universal principles, whether he likes it or not. They will generate within him natural tensions, prompting new creations." 61

Complementary colors are opposite each other on the color wheel. When their pigments are mixed together, they yield a neutral gray-black. "They incite each other to maximum vividness when adjacent; and they annihilate each other, to gray-black, when mixed . . . $" 62$

Matisse's Le Piano, 1916, was shown to illustrate one use of complementary colors. It was noted that the dominant color is a combination of green and gray-green. The pink and green are complementary as are the blue and red-orange, and "all colors are of equal briliziance...."163

59 Anderson, p. 127.

60 Anderson, p. 124.

6 Itten, p. 26.

62 itten, p. 78 .

63 Itten, p. 100. 
Van Gogh's Portrait of the Artist, 1890, was shown to illustrate his statement as quoted by Anderson as he considered the action of complementaries, "There is no blue without yellow and orange." 64 this painting also exibits color domination by analogous colors in the blue range.

Analogous colors are next to each other on the color wheel, "especially those in which we can see one common hue." 65 "inalogous colors, through their relationships, create spatial movement, and contrasting colors provide varied accents or vocal [sic] points of interest. Both are used to exploit the limitless dimensions of space. 166

An old, red kerosene lantern was used as the only subject matter for this assignment. Three two-dimensional views of the lantern, front, side, and plan or top were to be drawn on three different pieces of tracing paper. Students were to explore the design possibilities of these three views through juxtaposition, overlap, transparencies, and fragmentation to express "the idea of the object rather than only one view of it." 67

In line with reproductions shown, students were to establish a dominant color relationship using two or three analogous colors. The complementary of the most dominant hue was to be used to explore the effect of color contrasts. White, black, gray, and the complementary

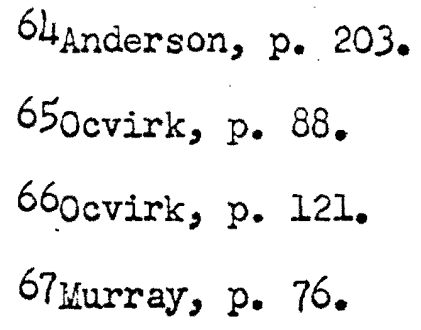


hue were to be used for value changes. They were to experiment with grayed colors in the manner of the cubists. Full intensity colors were to be held at a miniroum to reverse the attack of problem two where primary colors were used at full intensity.

Students were encouraged to use texture in one form or another if they desired.

They were advised to work through the painting with one hue or value at a time to try to establish rhythm and balance through shape and color relationships. "Rhythm is the continuance; a flow, which is affected by reiterating and measuring related, sinilar or equal parts." 168

"Since the design process involves color relationships [sic] it is best to establish tentative relationships all over the working surface at the very outset,... they suggest what is to be done next." 69

The class critique revealed this assignment to have been one in which all students had become enthusiastically involved. They were delighted and surprised at the variety of color relationships and compositions which were exhibited.

This author was delighted that some students had searched for more and different views of the lantern than had been assigned to use in their paintings. They expressed appreciation for the paintings themselves and not for object recognition or delineation as in previous classes. They observed that, "The function of representational

$$
\begin{aligned}
& 68 \text { Ocvirk, p. } 27 . \\
& 69 \text { Anderson, p. } 203 .
\end{aligned}
$$


clues in cubist paintings... Is to narrow down the range of possible interpretation till we are forced to accept the flat pattern with all its tensions." 70

Some students had found it difficult or impossible to gray their colors while others had retained an interest for values from the chair painting and had grayed all their colors. Some had become too involved with analogous colors and had neglected the use of complementary colors.

Students discussed each painting objectively and noted these discrepancies in relation to the assignment. However, they also pointed out contrasts of color, light and dark, and warm and cool which they felt were important enough to establish a proper degree of dominance or emphasis. "Each particular part of a picture should receive its proper degree of dominance, [sic] or emphasis. In order to merit attention, a featured part. should be in contrast with its surrounding area."71

They expressed concern that "To conserve the energies of the viewer, a work of art should be rhythrically articulated. Without a rhythmic order of any kind, a picture surface would be fatiguing and chaotic. 172

They observed that they had been working to simplify the shapes of the object into flat shapes in space and that color had again exhibited its advancing and receding characteristics.

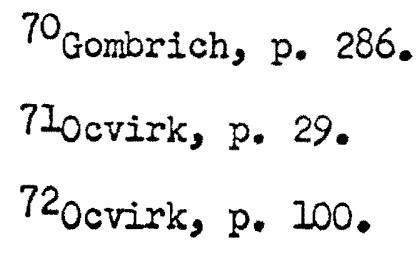


Finally, they began to realize "... that a picture can have a life of its own, and that the creation of space is not essentially a matter of portrayal or rendering..." 73

Problem 4 .

A print was assigned for the last problem of this paper. Students had previously taken a field trip to view the Artists of Oregon Show at the Portland Art Wuseum. They also made a tour of the Nuseum Art School where they saw the print show of George Johanson, Portland artist and teacher.

Students were to choose their own subject matter for this assignment. Visual objects were to be simplified in line with previous assignments with emphasis on boldness of design and clarity of color. Designs were to be considered in terms of flat patterns and large flat shapes which are most conducive to reproduction from Iinoleum blocks. 74 At least two colors were to be used in addition to the color of the paper. It was emphasized that "A print, more perhaps than any other medium, depends peculiarly on the overall power of its design."75 Therefore, the principles of design, particularly balance, emphasis, and contrast, were to be given considerable concentration.

Shapes other than the rectangle such as circles, diamonds, and hexagons were suggested as picture planes for their designs. The idea of a frame within a frame presentation of related pictorial elements

730 cvirk, p. $122 f$.

74Darvey E. Carlsen, Graphic Arts, 4th ed. (IIlinois, 1970), p. 102.

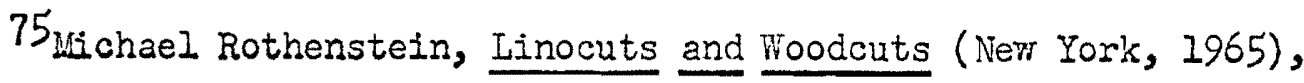
p. 13.
} 
was suggested and discussed. In this connection, the following original prints were shown and exhibited in the room:

$$
\begin{aligned}
& \text { Gardner, Byron. Falling lan, } 1966 . \\
& \text { NcLarty, Jack. The Body of the Dreamer, no date. }
\end{aligned}
$$

Since most of the students had had some experience with linoleum printing, a combination of printing techniques was to be exployed. Some alternatives were suggested by Byron Gardner's print and by George Johanson's print show where hardboard was used as a raised surface and shellacked.

In this respect, students were advised that prints would be considered as a legitimate means for original expressions, and their results should be judged, as they are judged in painting and sculpture, by virtue of this quality above all else without the inhibiting influence of craft for its own sake. 76

Students were reminded that their designs would appear as a reverse image or "mirror-reflection" of their blocks. Transparent tracing paper was used for their original designs so that they could be turned over and traced onto the blocks to achieve the printing of the design as originally planned.

This problem was stimulating to the students after they had once decided on a subject matter idea, the related pictorial elements to be employed, and the manner of presenting the pictorial elements. Some students had to be reminded of previous problems when it was felt that a regression involving minutiae was occurring in their presentation of the pictorial elements. 
On critiquing the finished prints, students noted the variety of subject matter and the imagination exercised in the designing of pictorial elements to express their thoughts, ideas, and feelings. They indicated the awareness that "Our world is too complex to understand, keep track of, or express in total, so the problem is broken dom into parts . . Only in this way do we make sense of the environment." 77 They considered the contrasts of line, shape, color, texture, and space as they moved the eye over the picture plane as "moving and directional forces which must counterbalance one another so that a controlled tension results."78 They referred back to the black dot problem often expressing concern that "The painter is forever concerned with the thrusts and pulls of line, volume and color which can become very complicated."79 and, therefore, ".. shapes should be placed in positions which will contribute to the total balance of all the involved picture parts and that other elements can put a pictorial arrangement 'in' or 'out' of balance according to their use." 80

They compared the "feeling" of balance between parts of the various designs and discussed the dynamic and expressive organizations. They discussed opposing forces and their tensions as they related to asymmetrical or symmetrical balance.

Since this type of assignment was new to them, most students felt that, after the initial frustration of choosing subject matter

$$
\begin{aligned}
& 77_{\text {Anderson, p. } 97 .} \\
& 78_{\text {Ocvirk, p. } 24 .} \\
& 79_{\text {Watson, p. } 83 .} \\
& 80_{\text {Ocvirk, p. }} 23 f .
\end{aligned}
$$


had been overcome, it made learning more exciting and had motivated them to greater exploration and creation. 
CHAPTER IV

CONCLUSION

An artist, then, is simply one of many who, in editing the enviroment, take from it that which they deem pertinent, leaving out much that confuses, relocating substructures, and summing up scattered detail into comprehensible units. The image presented to an audience is thus an abstraction, and the process outlined is the process of design. 81

In this study on simplification of a subject and establishing an underlying structure to emphasize the monumental aspects of a subject, it was necessary to press forward in a rather limited direction. This does not intend to infer that elaboration and complexity are negative qualities in graphic expression but that they would be another unit of study based on this one wherein the subject was strioped of minutiae and selection was emphasized.

Because most beginning art students have selaom looked at a work of art in any other sense than to recognize objects, it was felt that this program contributed to the pleasures of informed looking and enjoyment of those art works from committed artists as well as presenting the necessity of manipulating objects and field areas in the process of picture making.

In this respect, students were now volunteering to research and make slide presentations to the class on artists in whom they had developed a particular interest or asking to be assigned an artist who

$8 I_{\text {Anderson, p. } 97 .}$ 
might be of interest to them and to the class. They have expressed greater interest in other art movements since their experience with cubism. Two reports have already been made, one on Paul klee and one on Henri datisse.

In general plan this unit sought to lay a foundation for picture planning and picture viewing. The problem began with easy exercises in simplification and space and proceeded gradually to the more difficult projects with emphasis always on flat shapes on a two-dimensional surface.

With each new problem a vocabulary was introduced. Explanations were offered as to why such problems should be investigated.

The students produced a variety of work, which showed them that there was more than one way of doing things, even though they were restricted to certain limitations, such as using only one color and one object.

Students began to understand that a background of fundamentals, once learned, would make them freer to make creative decisions. Critiques of work exhibited at the completion of a problem offered the student an opporiunity to verbalize on creative decisions, his own and others. Arguments were not uncommon during these sessions. This author considers this to be a healthy activity. It confirms the fact that students are actually beginning to look at art, maybe for the first time, and offering an opinion.

This unit may have been a partial answer to a problem of adolescence, as Anderson puts it:

It is recognized that the art of children is candid in selfrevelation. When a child comes into adolescence [sic] he 
realizes that his outrageously honest commentary may not continue if his position in the family and social environs, school, playground, and church is not to be marred by scenes of violence. We put away that which is childish and speak, dress, and act in adult fashion. In speech, which is ephemeral, more care is taken, and in art, a permanent record, it is 'No comment', a complete blank. Control of fine movernents improves but the expression of personal view declines. It is important to realize that this particular problem exists. It is both possible and necessary to rediscover areas of personal interest in the environment which can be successfully explored. 82

82 Anderson, p. 106. 


\section{A LIST OF WORKS CONSULTED}

Anderson, Donald M. Elements of Design. New York, 1961.

Carlsen, Darvey E. Graphic Arts, 4th ed.. Illinois, 1970.

de Sausmarez, Maurice. Basic Design: The Dymamics of Visual Form, ed. Johin Lewis. New York, 1904.

Gettings, Fred. You Are An Artist. London, 1965.

Gombrich, E. H. Art And Illusion, 2nd ed.. Tennessee, 1965.

Itten, Johannes. The Art of Color, trans. Ernst van Haagen. New
York, 1961.

Loran, Erle. Cézanne's Composition, 2nd ed.. California, 1946.

Murray, Peter and Linda. A Dictionary of Art and Artists, 3rd ed.. Great Britain, 2963.

Nicolaides, Kimon. The Natural Way to Draw. Boston, 1941.

Ocvirk, Otto G., Robert Bone, Robert Stinson, and Philip Wigg. Art Fundamentals. Iowa, 1960.

Rothenstein, Kichael. Linocuts and Woodcuts. New York, 1965.

Watson, Ernest $w_{0}$ Composition in Landscape and Still Life. New York, 1959.

Webster's New World Dictionary, College Edition. New York, 1956. 

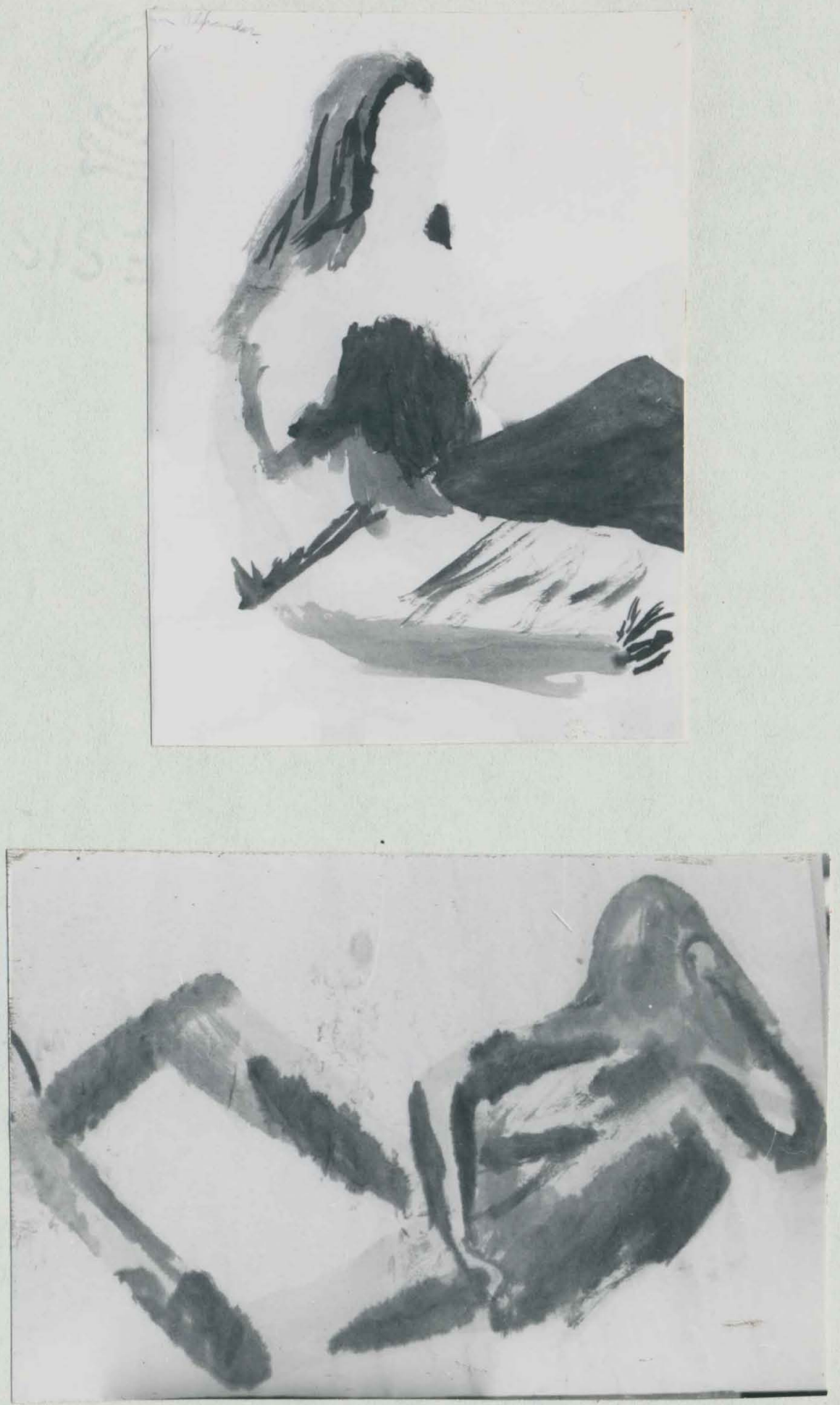

Figure 1. Results of Problem 2, p. 8. 

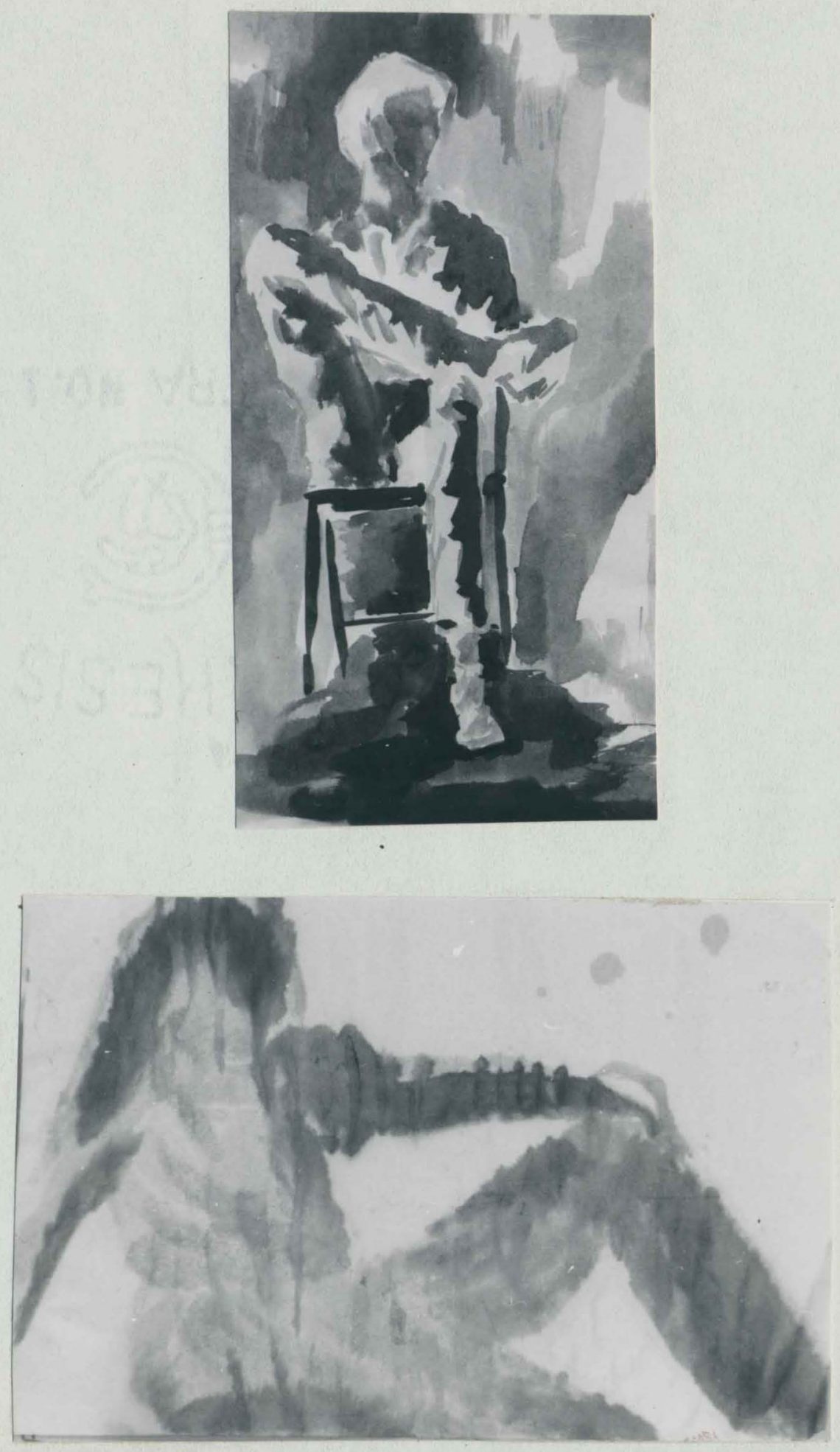

Figure 2. Results of Problem 2, p. 8 (continued). 

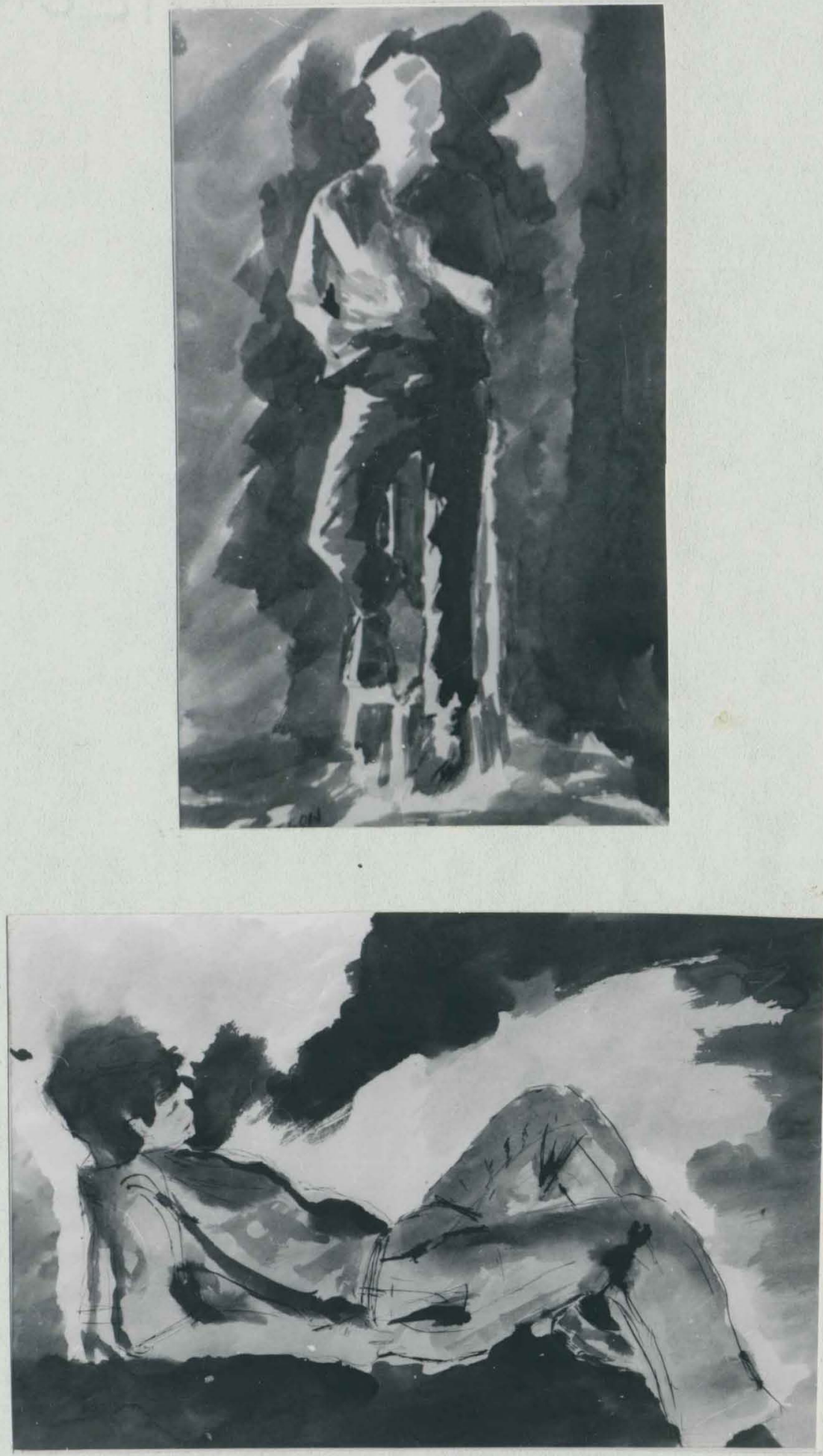

Figure 3. Results of Problem 2, p. 8 (continued). 


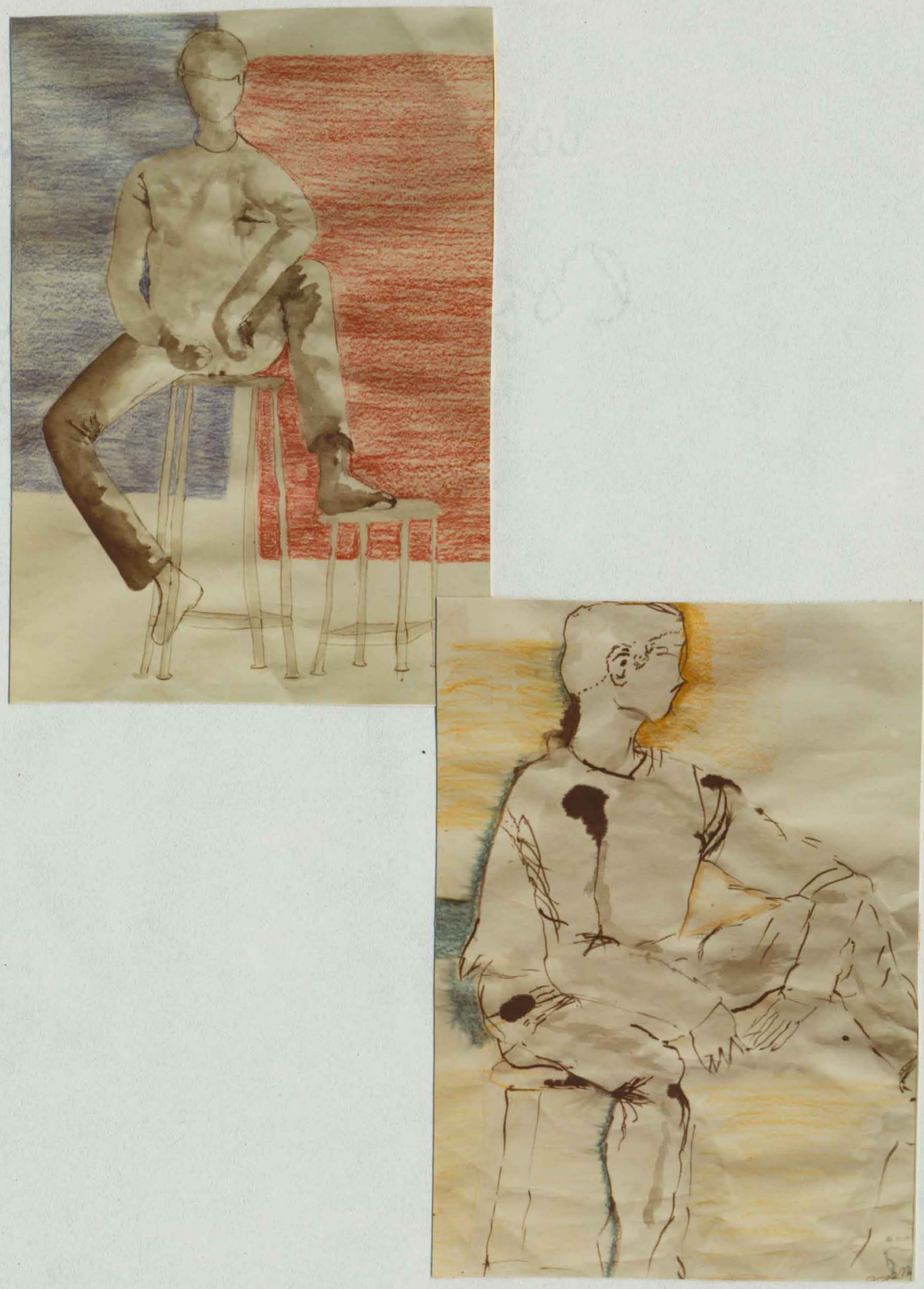

Figure 4. Results of Problem 3, p. 8. 

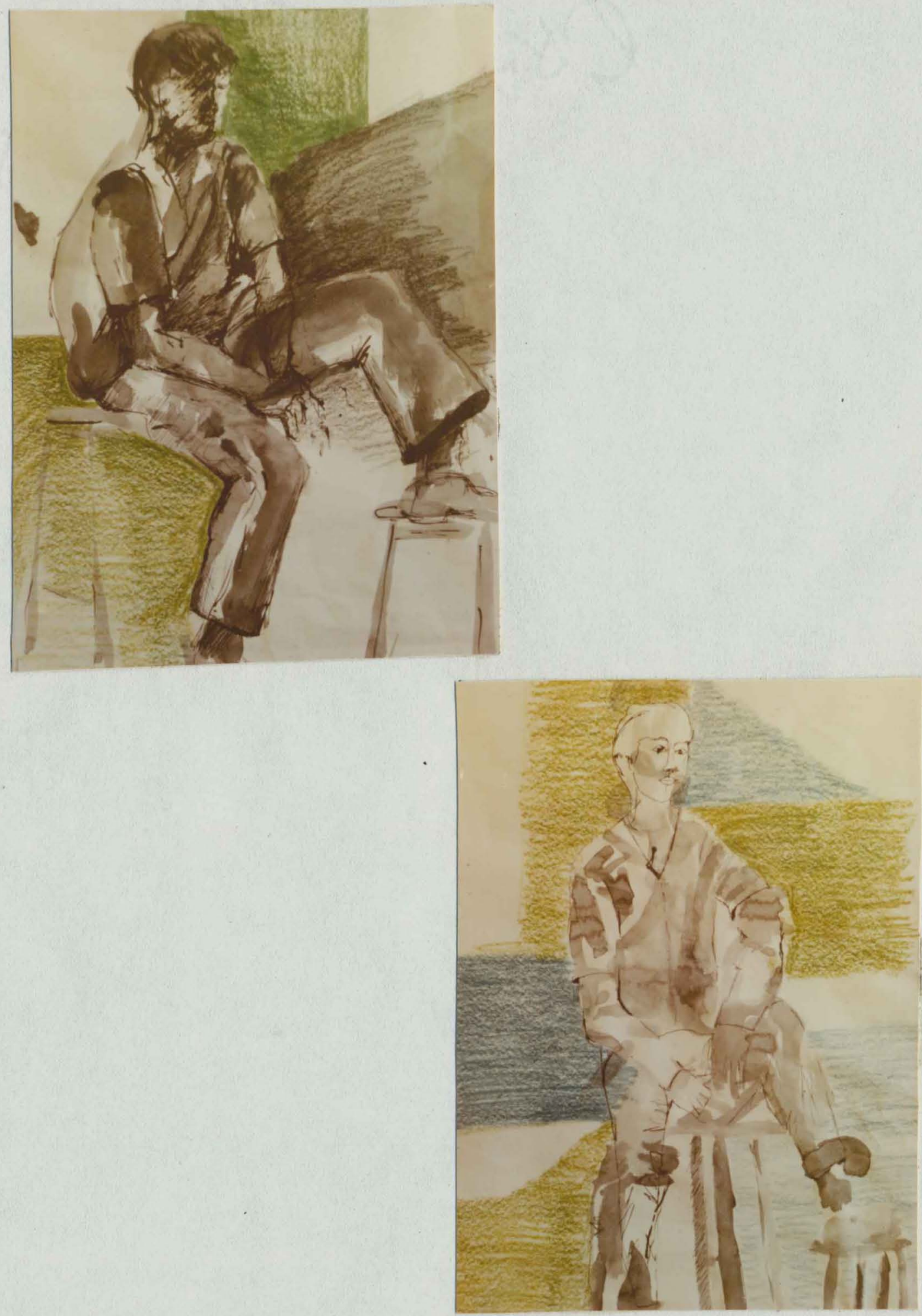

Figure 5. Results of Problem 3, p. 8 (continued). 

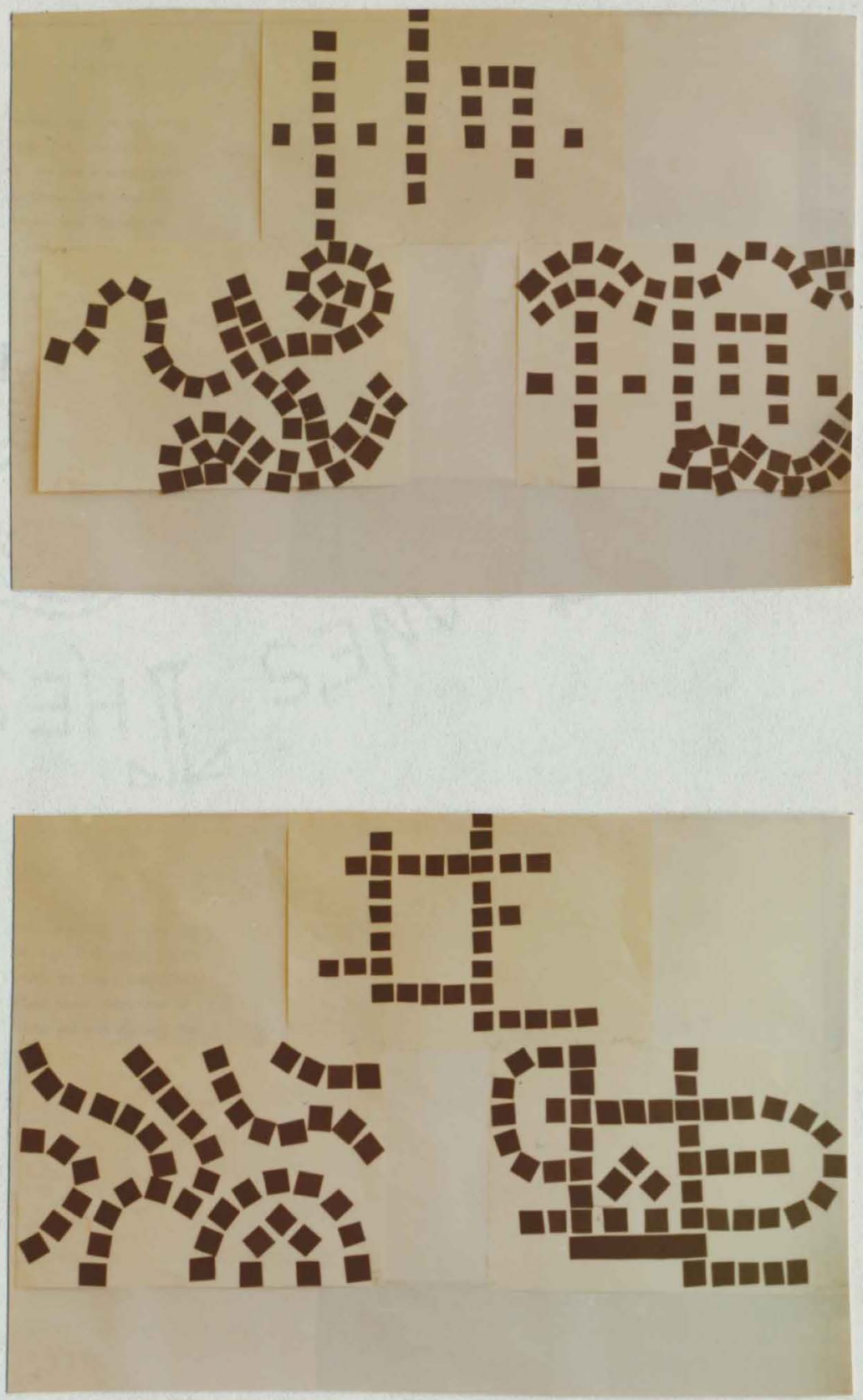

Figure 6. Results of Problems 1, 2, and 3, p. 10. 

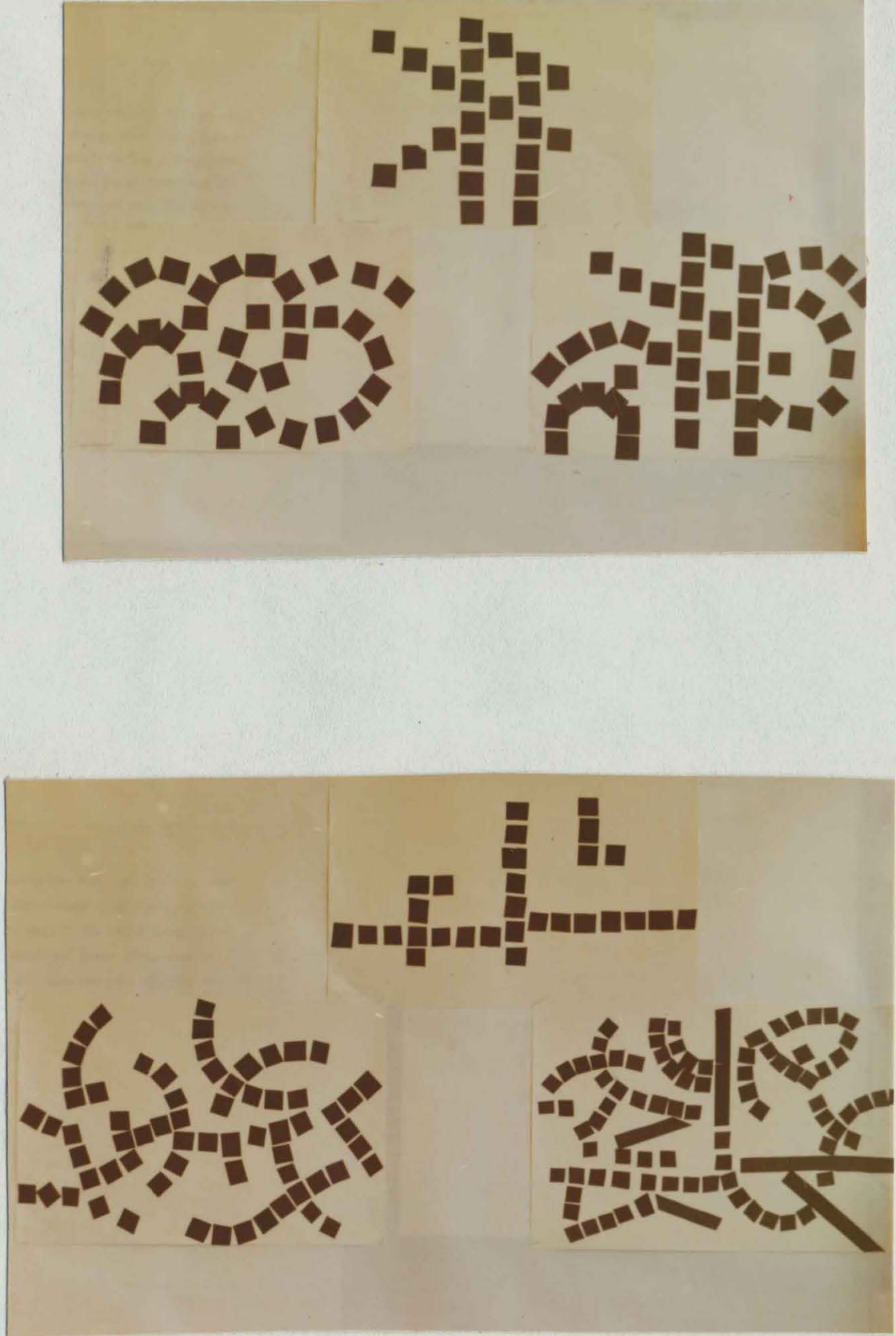

Figure 7. Results of Problems 1, 2, and 3, po 10 (continued). 

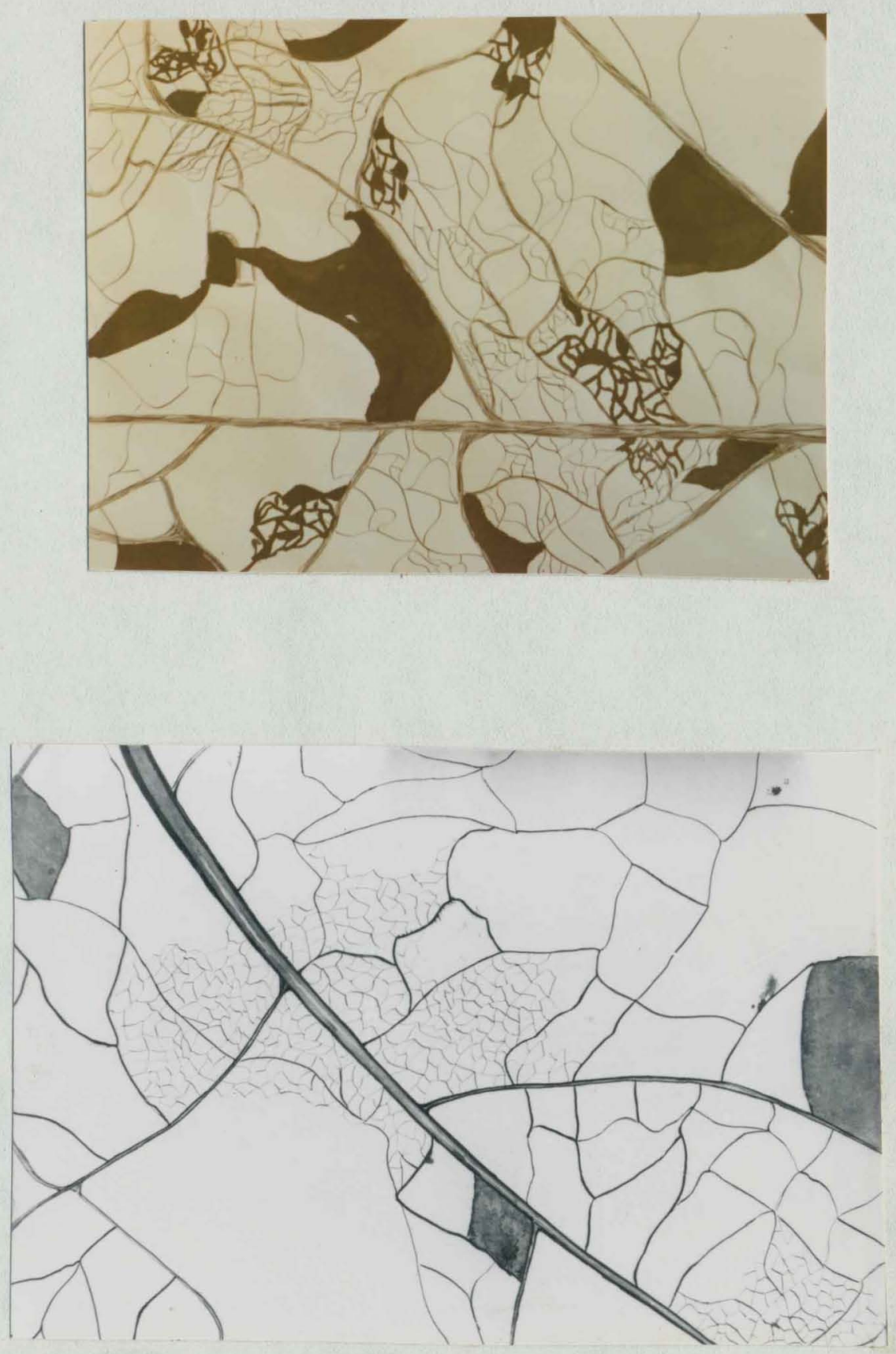

Figure 8. Results of Problem 4, p. 11. 


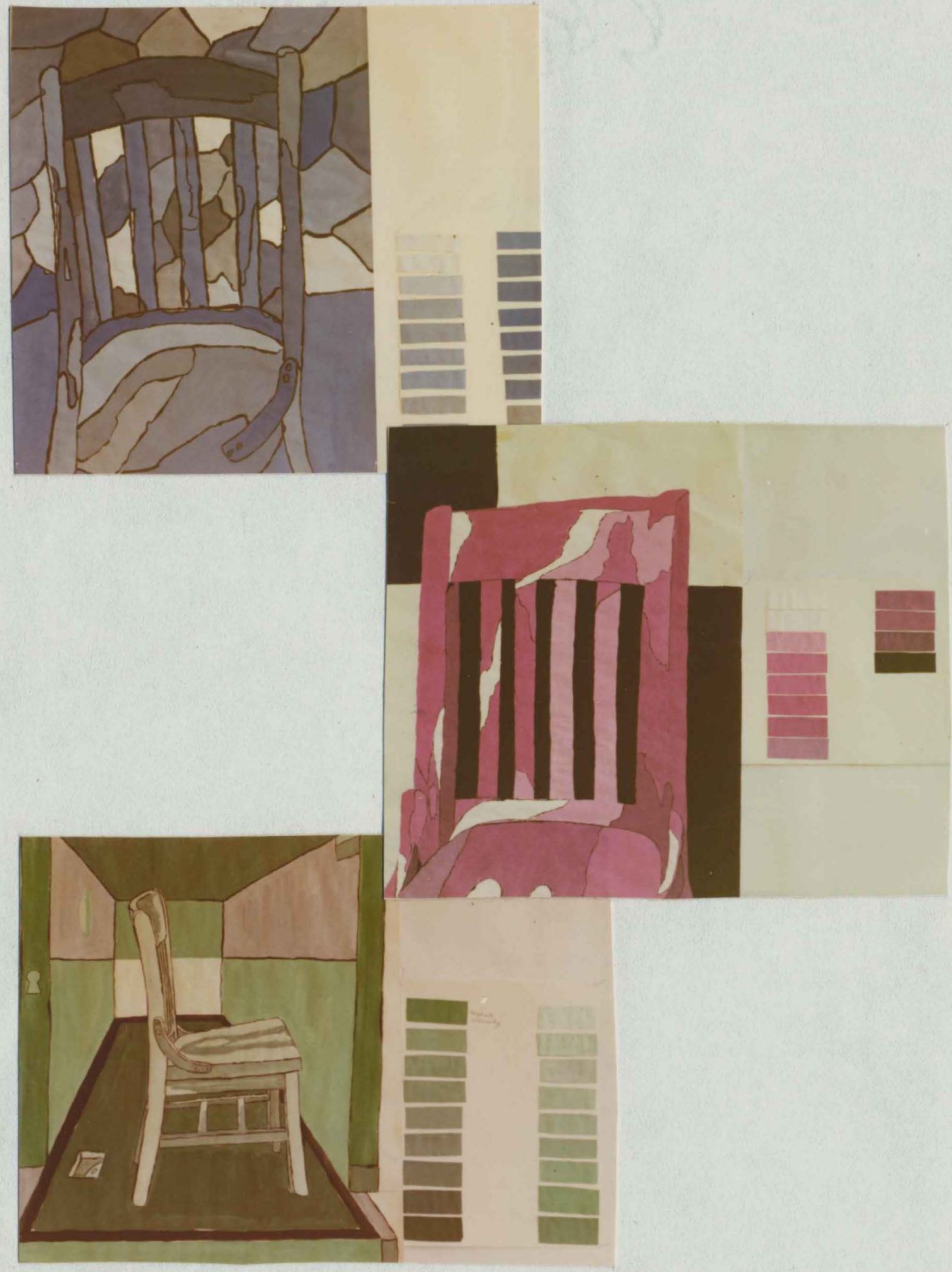

Figure 9. Results of Problem 1, p. 13. 


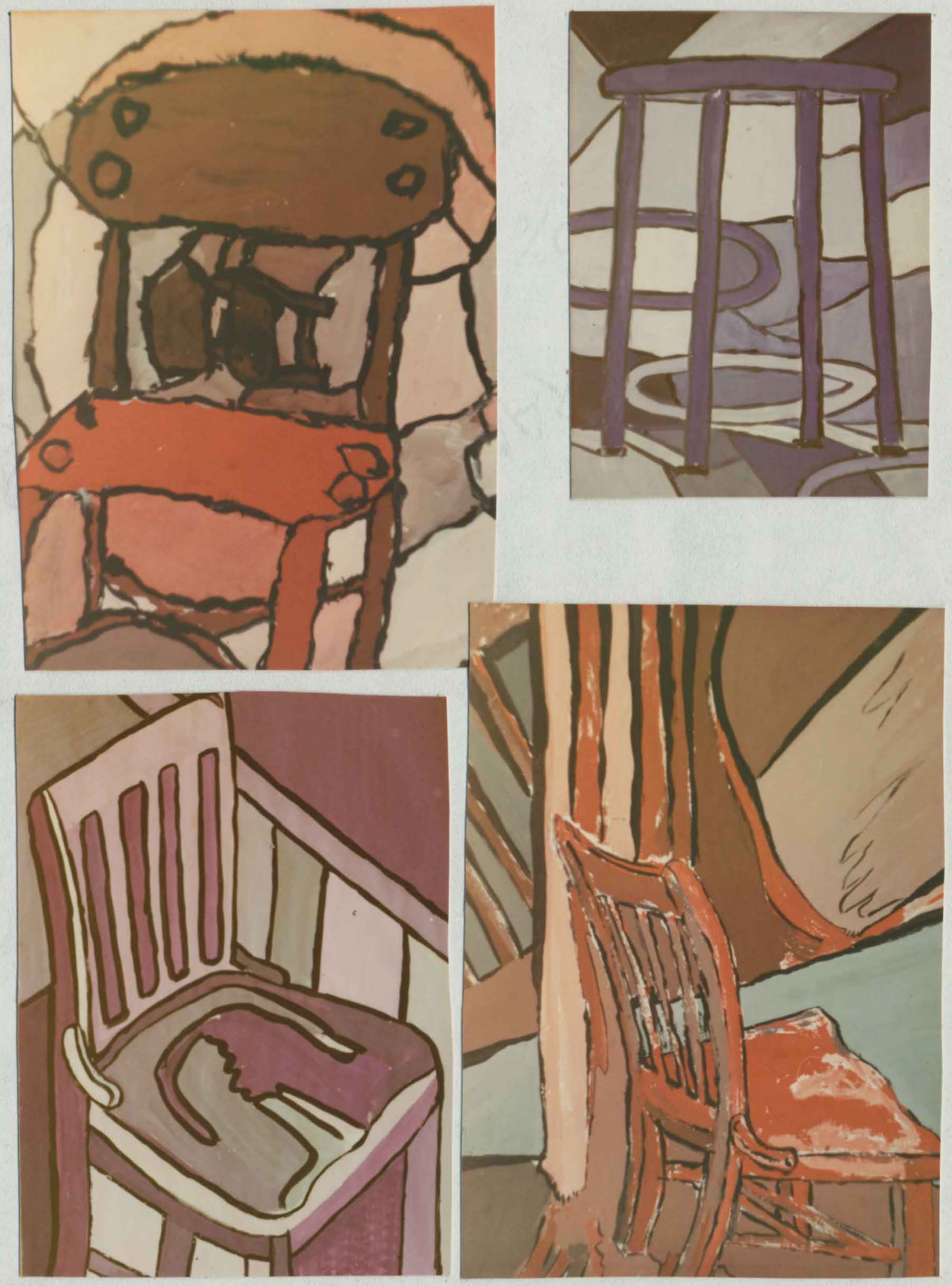

Figure 10. Results of Problem 1, p. 13 (continued). 

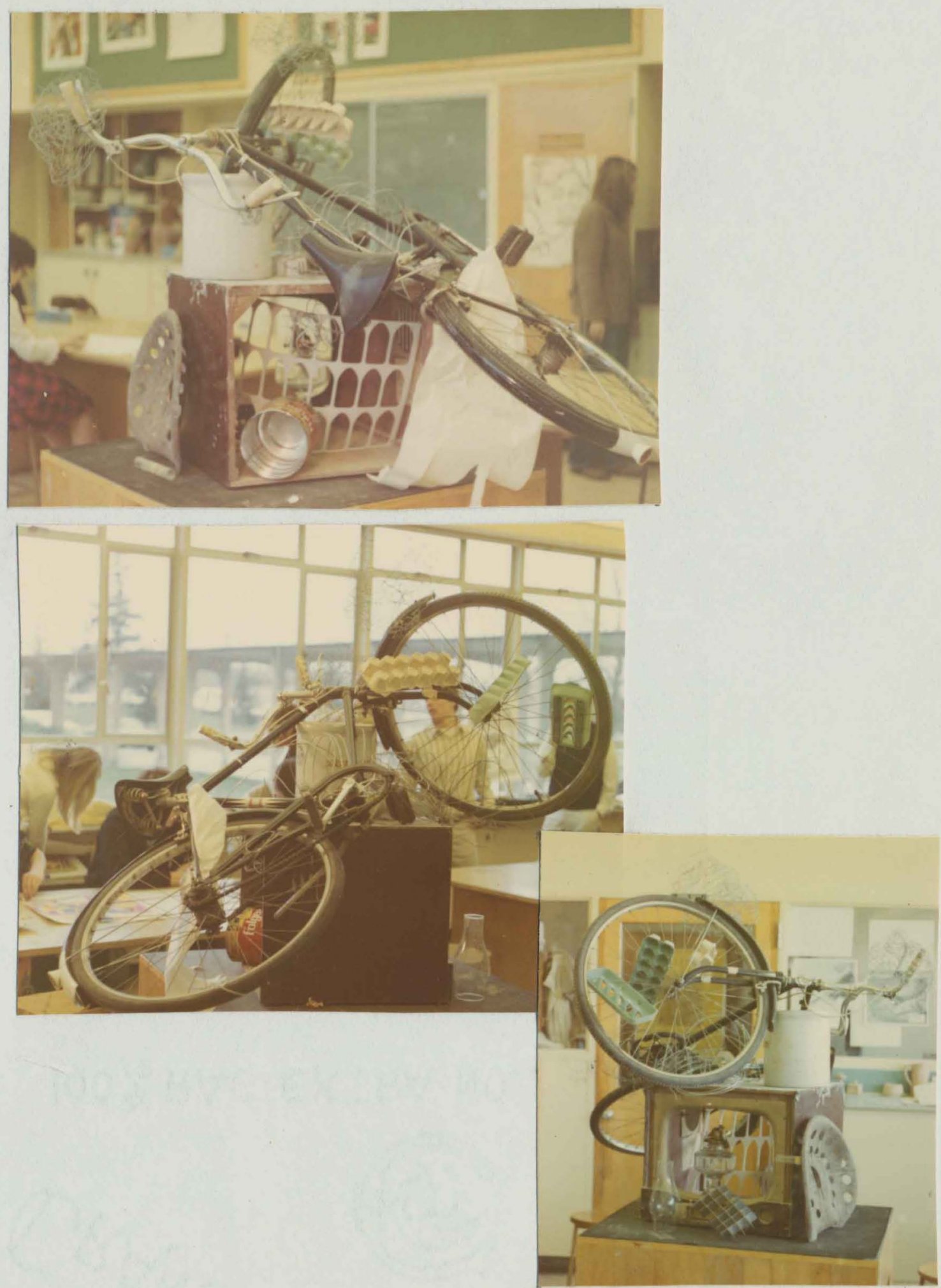

Figure 11. Three views of display, Problem 2, p. 15. 

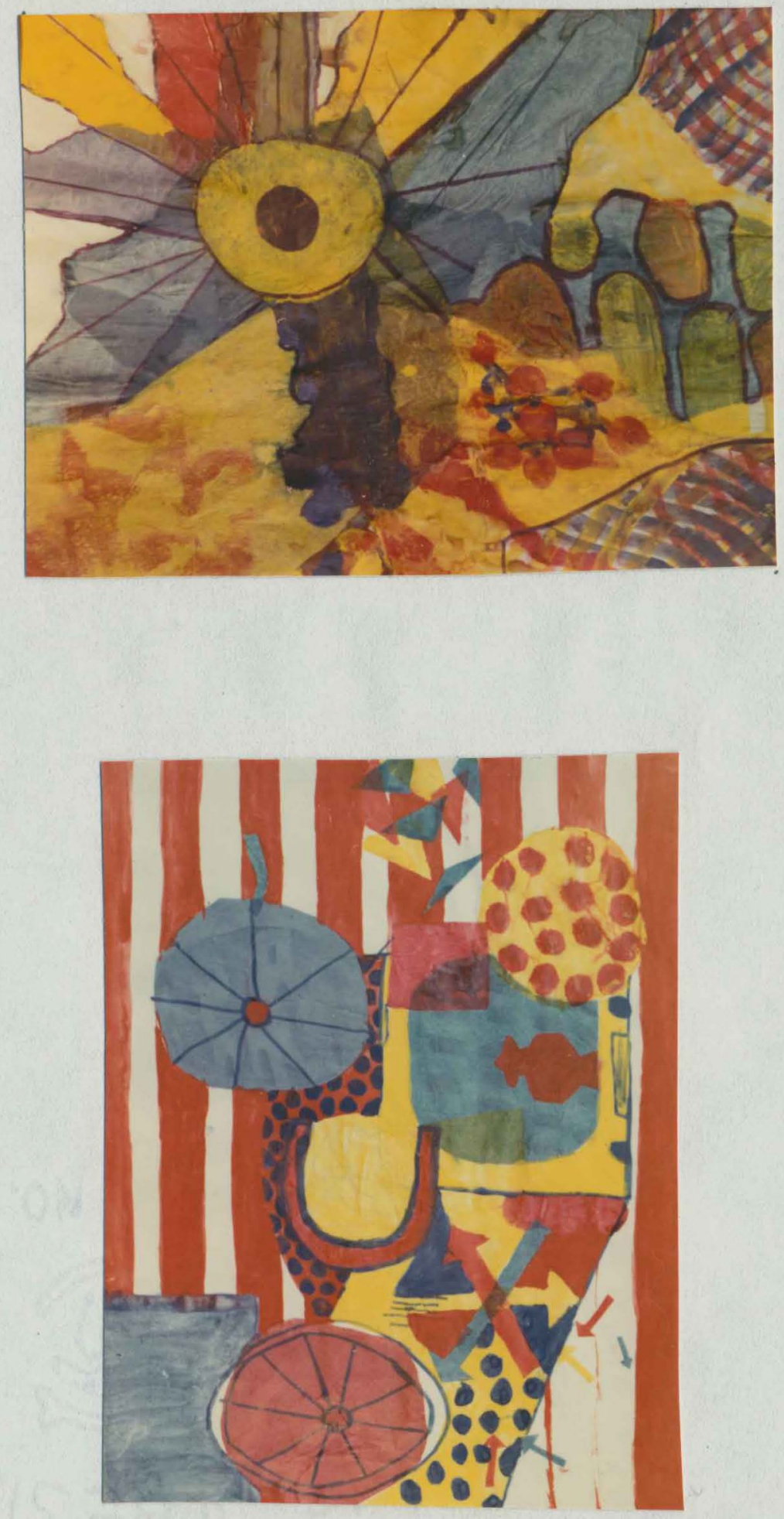

Figure 12. Results of Problem 2, p. 15. 

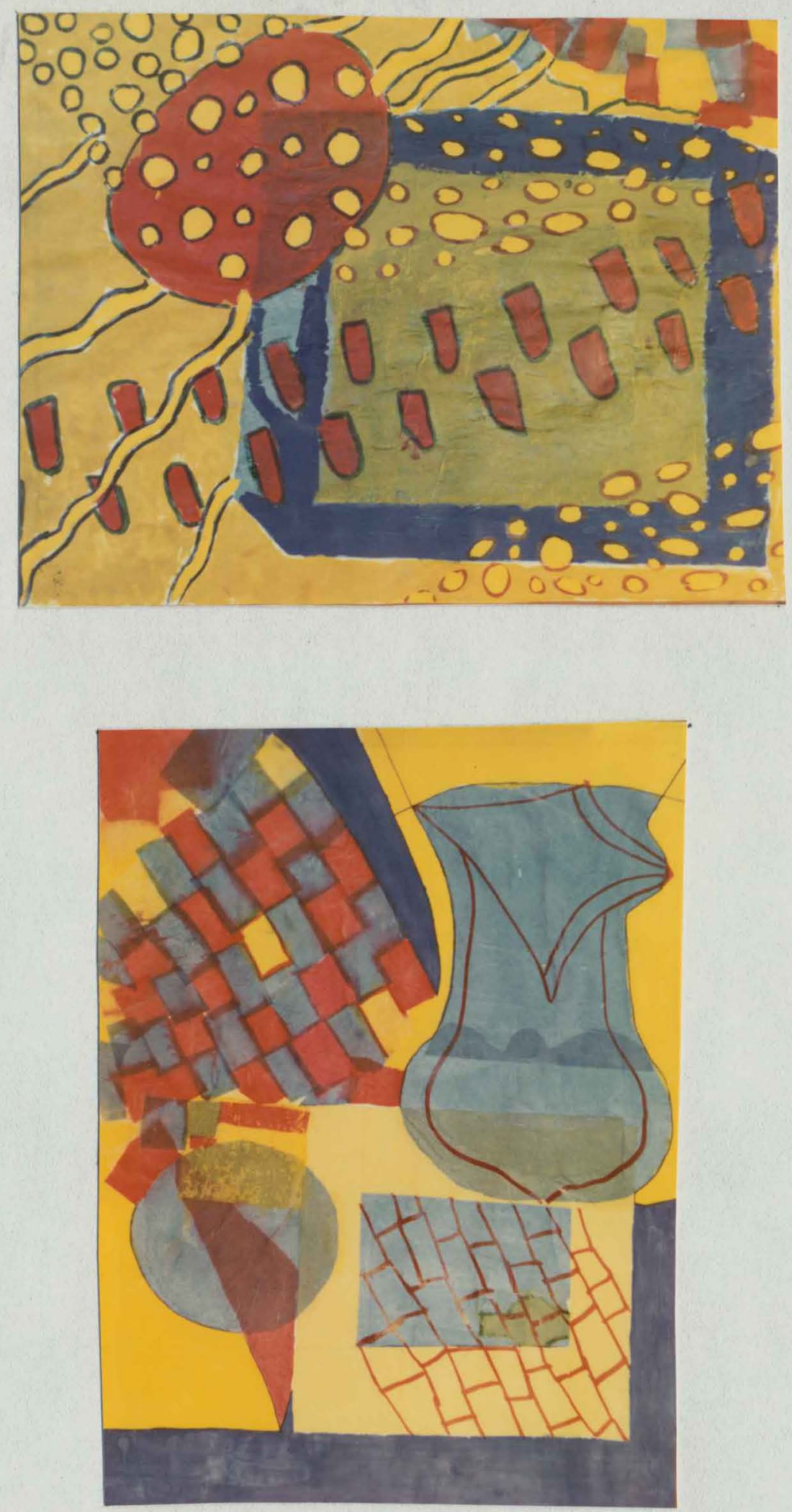

Figure 13. Results of Problem 2, p. 15 (continued). 

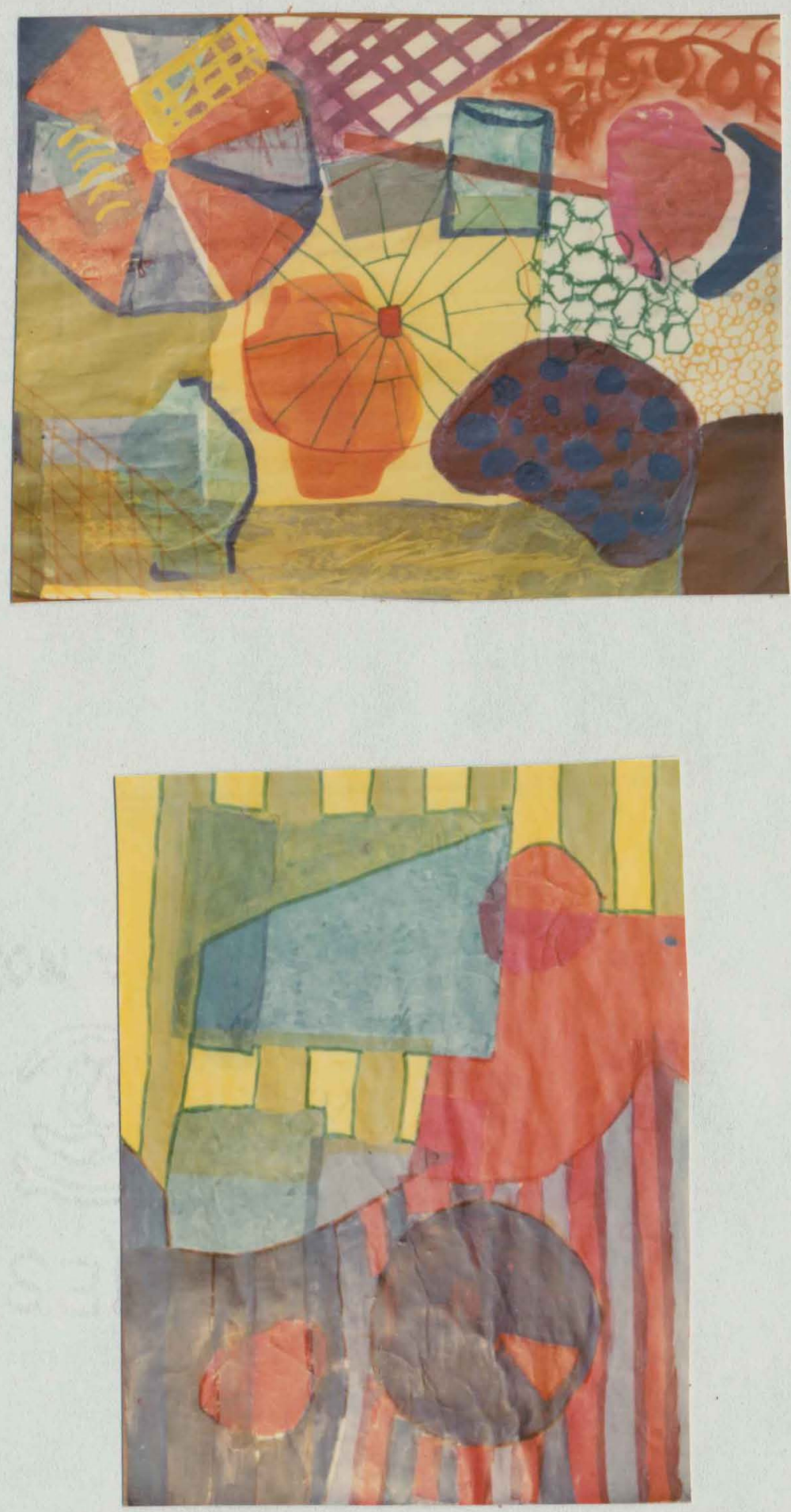

Figure 14. Results of Problem 2, p. 15 (continued). 

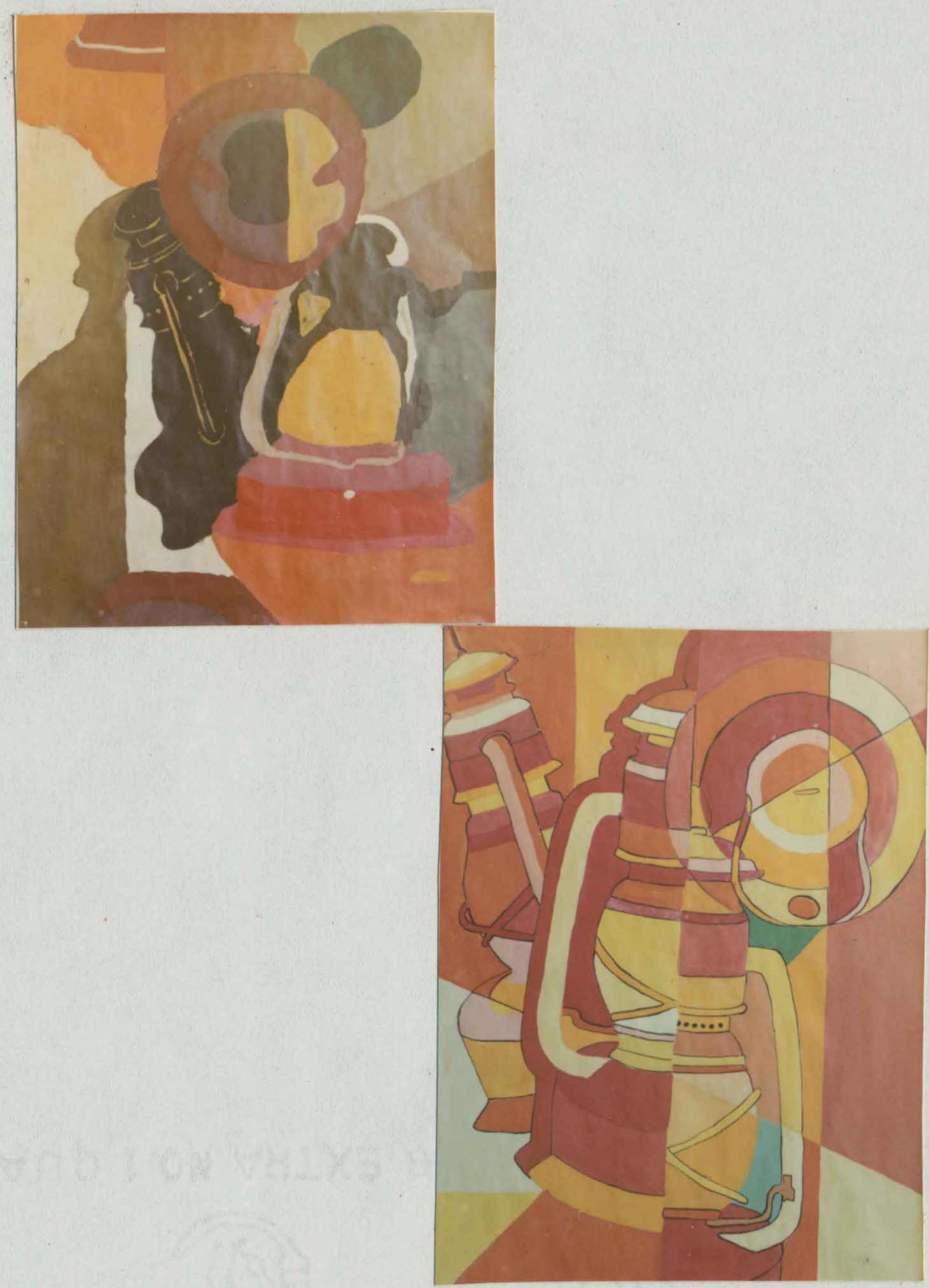

Figure 15. Results of Problem 3, p. 19. 

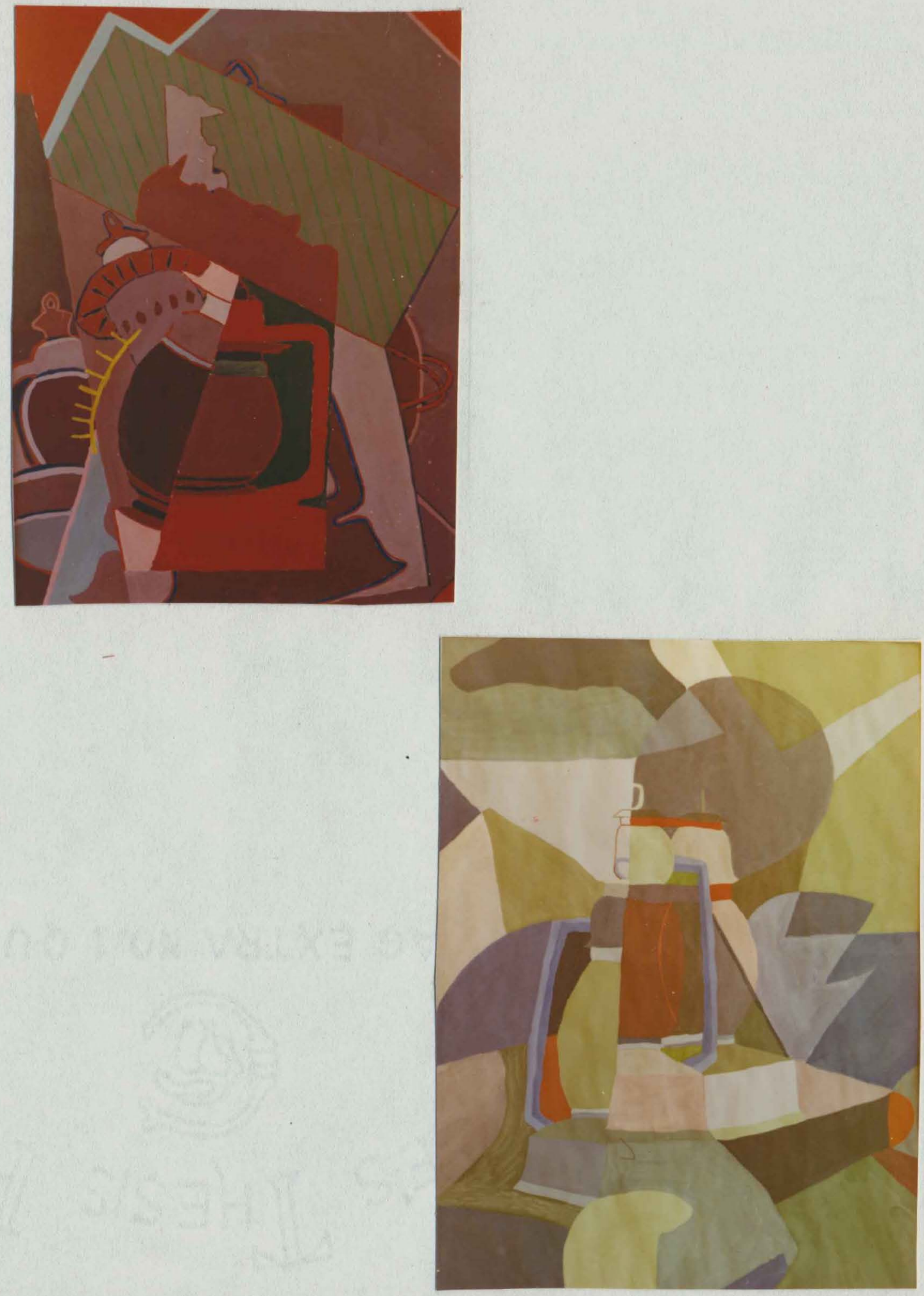

Figure 16. Results of Problem 3, p. 19 (continued). 

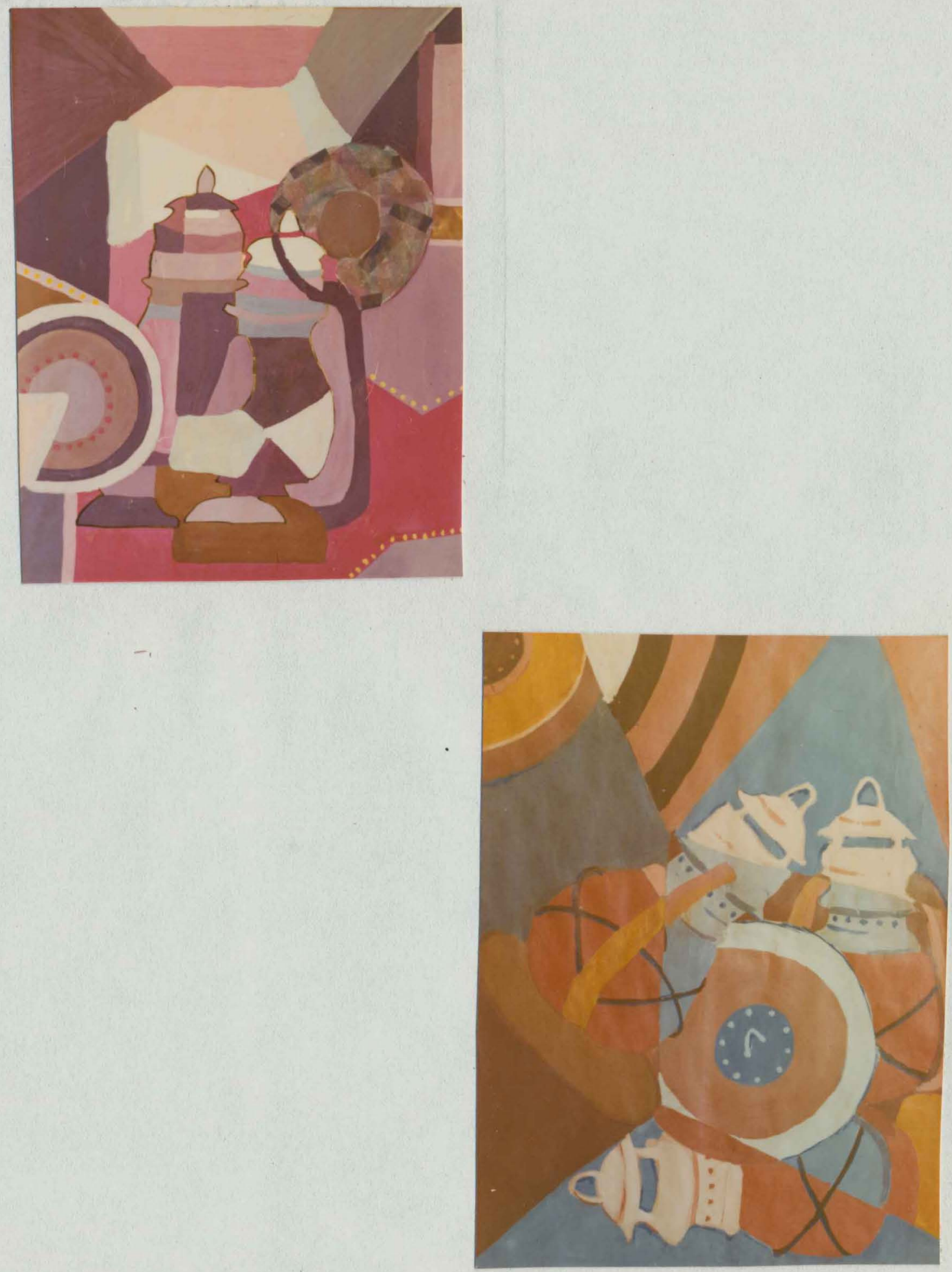

Figure 17. Results of Problem 3, p. 19 (continued). 

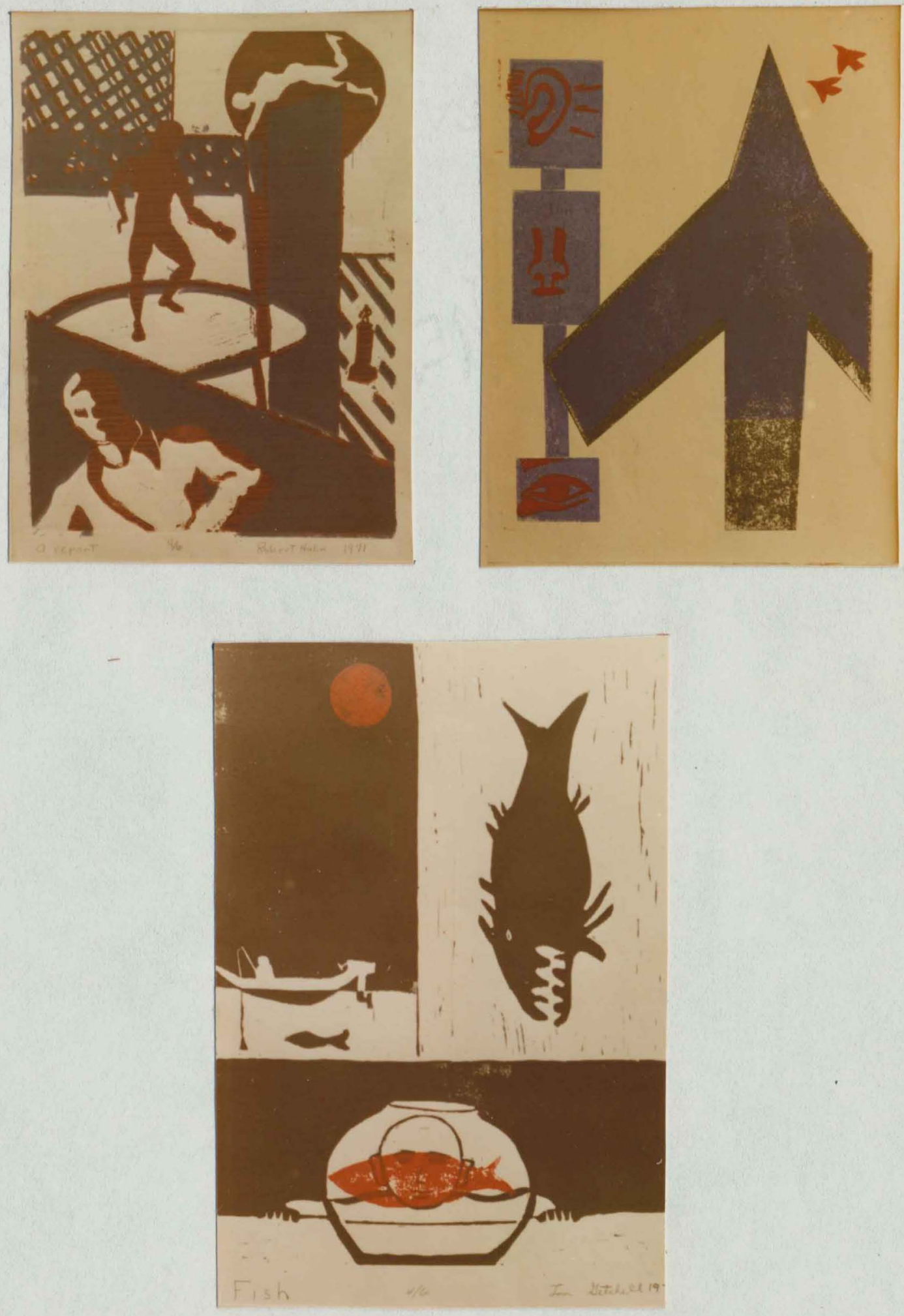

Figure 18. Results of Problem 4, p. 26. 

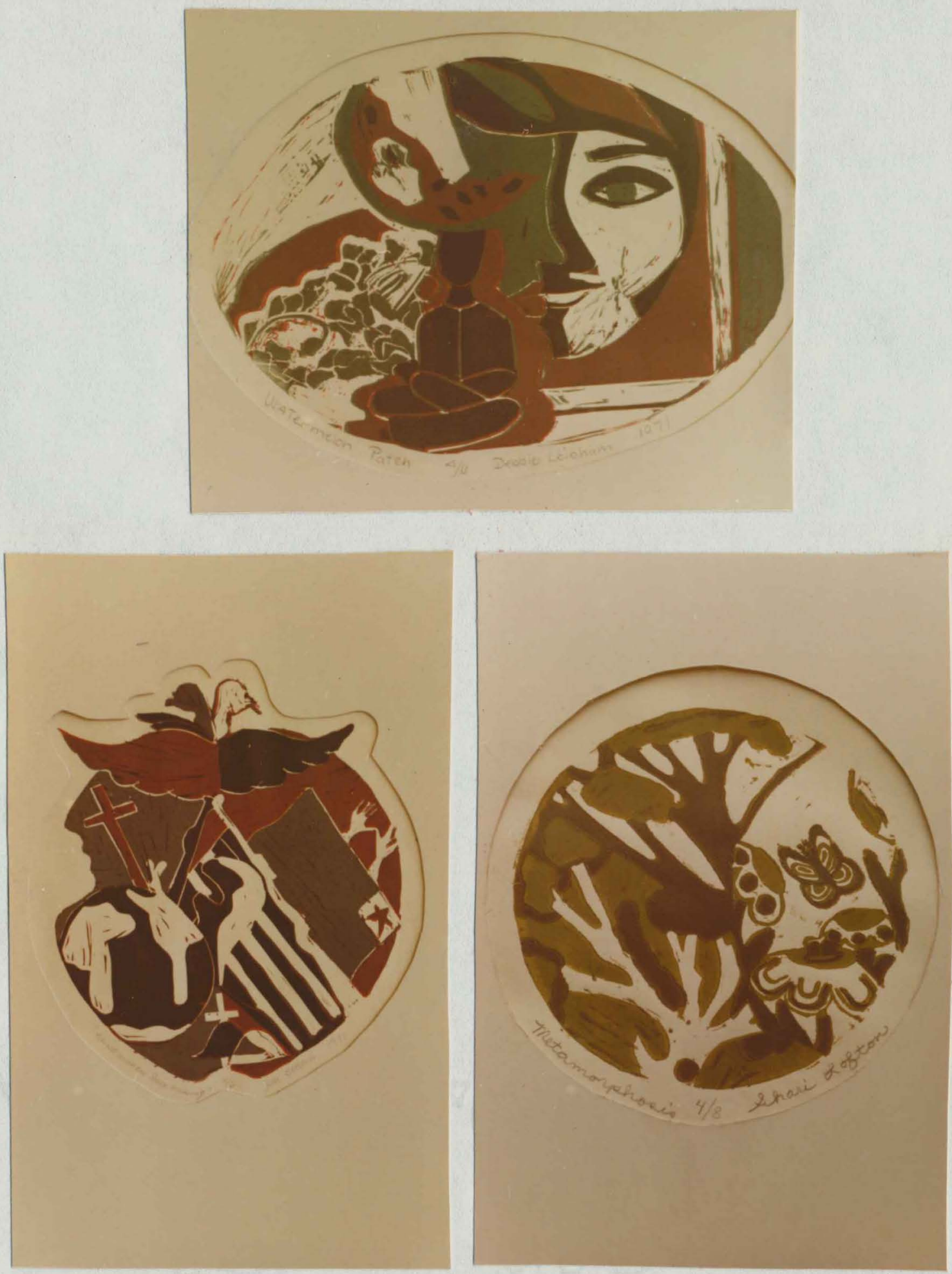

Figure 19. Results of Problem 4, p. 26 (continued). 

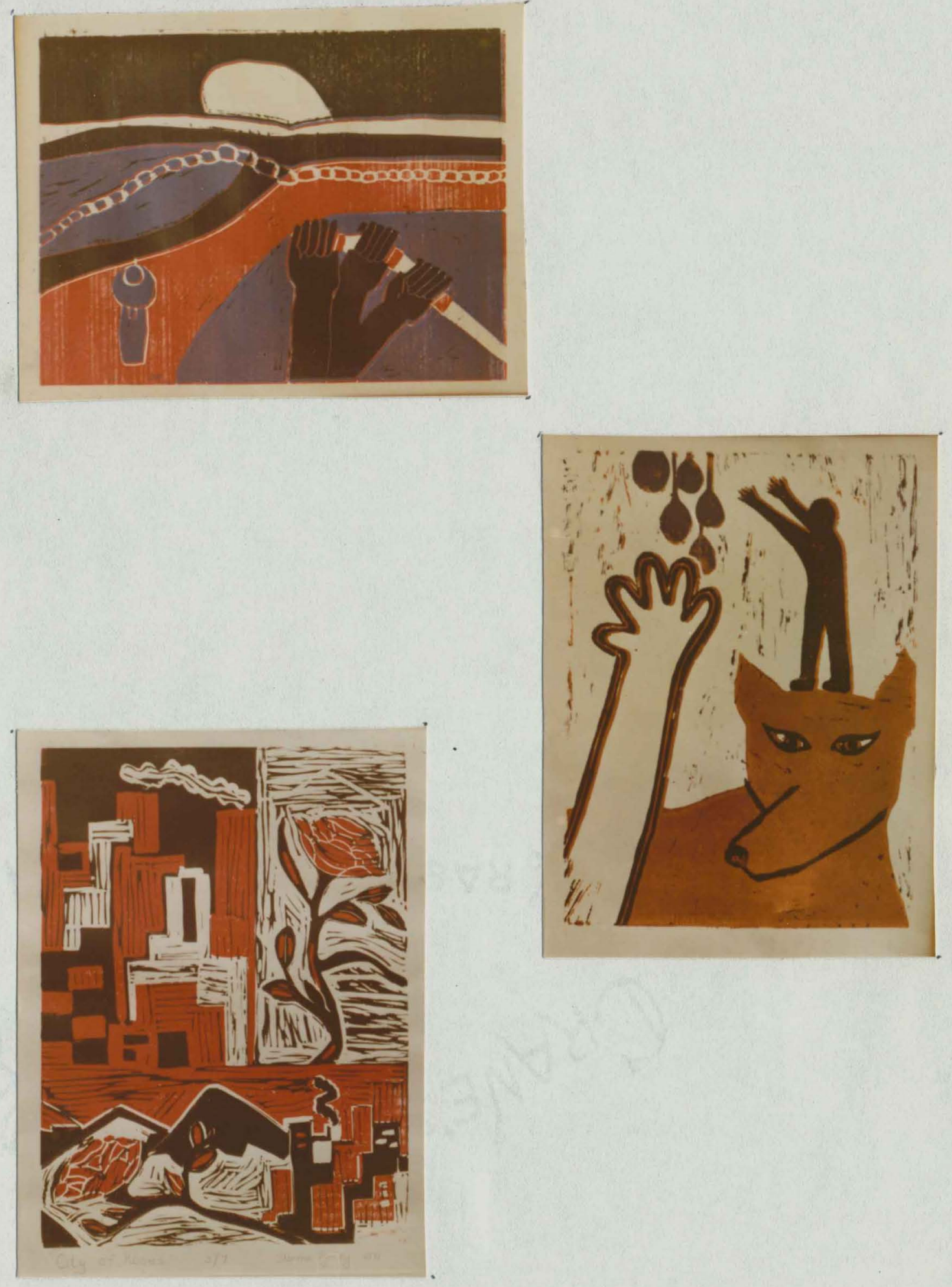

Figure 20. Results of Problem 4, p. 26 (continued). 

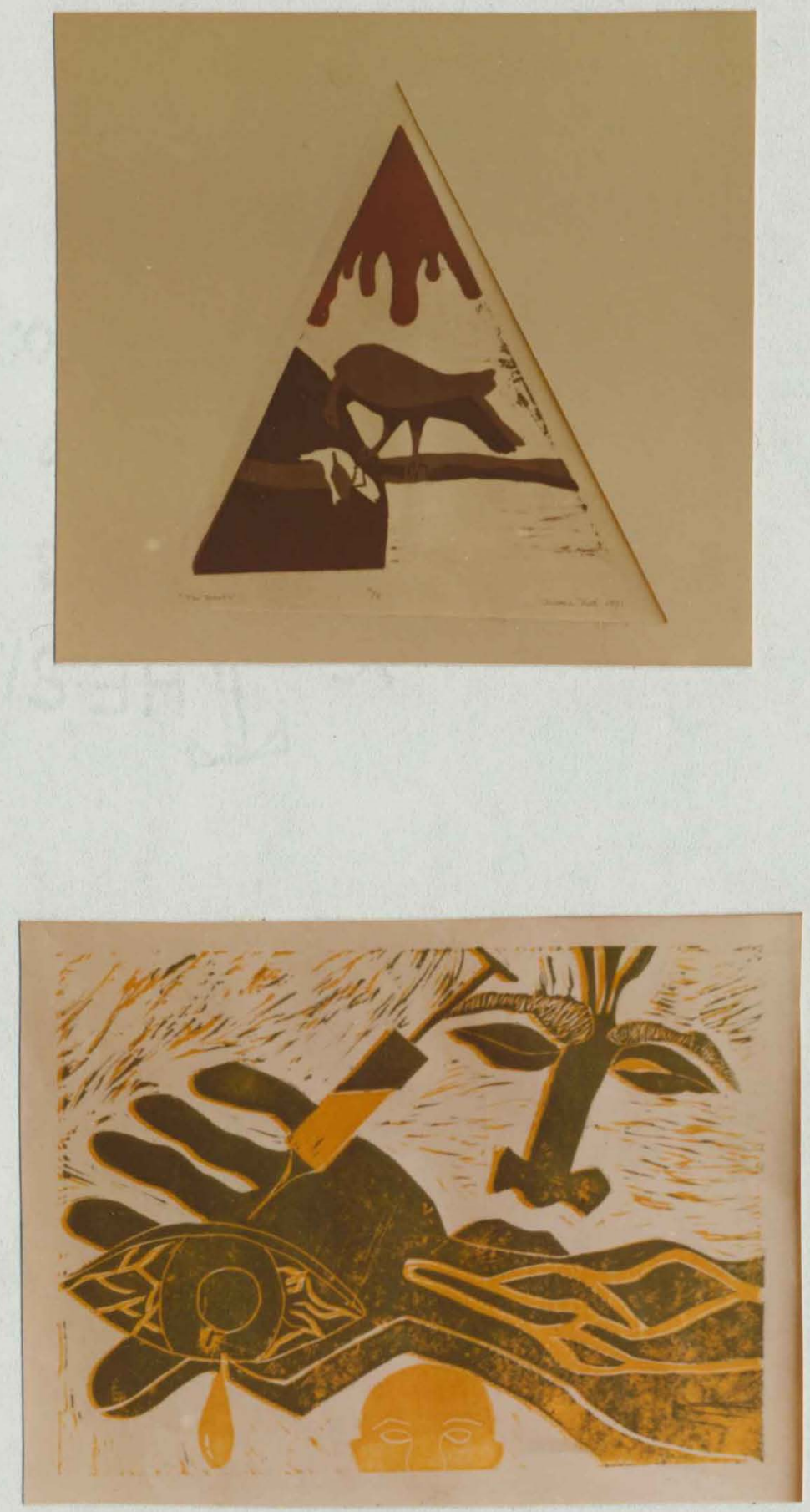

Figure 21. Results of Problem 4, p. 26 (continued). 